\title{
Immunomodulatory Monoclonal Antibodies in Combined Immunotherapy Trials for Cutaneous Melanoma
}

\section{OPEN ACCESS}

Edited by:

Leonor Kremer,

Consejo Superior de Investigaciones

Científicas (CSIC), Spain

Reviewed by:

Kerry S. Campbell,

Fox Chase Cancer Center,

United States

Zong Sheng Guo,

Harvard University, United States

*Correspondence:

Mariana Aris

mariana.aris@conicet.gov.ar

Specialty section:

This article was submitted

to Cancer Immunity

and Immunotherapy,

a section of the journal

Frontiers in Immunology

Received: 30 June 2017

Accepted: 08 August 2017

Published: 25 August 2017

Citation:

Aris $M$, Mordoh $J$ and Barrio MM (2017) Immunomodulatory

Monoclonal Antibodies in

Combined Immunotherapy Trials

for Cutaneous Melanoma.

Front. Immunol. 8:1024.

doi: 10.3389/fimmu.2017.01024

\begin{abstract}
Mariana Aris ${ }^{1 *}$, José Mordoh ${ }^{1,2,3}$ and María Marcela Barrio'
${ }^{1}$ Centro de Investigaciones Oncológicas - Fundación Cáncer, Buenos Aires, Argentina, ${ }^{2}$ Instituto Médico Especializado Alexander Fleming, Buenos Aires, Argentina, ${ }^{3}$ Fundación Instituto Leloir, IIBBA-CONICET, Buenos Aires, Argentina
\end{abstract}

In the last few years, there has been a twist in cancer treatment toward immunotherapy thanks to the impressive results seen in advanced patients from several tumor pathologies. Cutaneous melanoma is a highly mutated and immunogenic tumor that has been a test field for the development of immunotherapy. However, there is still a way on the road to achieving complete and long-lasting responses in most patients. It is desirable that immunotherapeutic strategies induce diverse immune reactivity specific to tumor antigens, including the so-called neoantigens, as well as the blockade of immunosuppressive mechanisms. In this review, we will go through the role of promising monoclonal antibodies in cancer immunotherapy with immunomodulatory function, especially blocking of the inhibitory immune checkpoints CTLA-4 and PD-1, in combination with different immunotherapeutic strategies such as vaccines. We will discuss the rational basis for these combinatorial approaches as well as different schemes currently under study for cutaneous melanoma in the clinical trials arena. In this way, the combination of "push and release" immunomodulatory therapies can contribute to achieving a more robust and durable antitumor immune response in patients.

\section{Keywords: monoclonal antibodies, immune checkpoint blockade, combined tumor immunotherapy, clinical trials,} cutaneous melanoma

\section{INTRODUCTION}

An important role for the immune system in cancer biology has been proposed for decades. However, immunotherapy has been very recently recognized as an effective treatment to control tumor growth and dissemination. Cutaneous melanoma (CM) is a highly mutated and immunogenic tumor and has been a rich field for the development of tumor immunology and immunotherapy (1-3). There is strong evidence of common tumor antigens (Ags) as well as patient's own tumor neoantigens

Abbreviations: Ags, antigens; APCs, Ag-presenting cells; CM, cutaneous melanoma; CTLA-4, cytotoxic T-lymphocyte antigen 4; DCs, dendritic cells; DFS, disease-free survival; ICKB, immune checkpoint blockade; ID, intradermally; IV, intravenous; IDO, indoleamine 2,3-dioxygenase; MDSC, myeloid-derived suppressor cell; MM, metastatic melanoma; mAb, monoclonal antibodies; neoAgs, neoantigens; OS, overall survival; PAMP, pathogen-associated molecular patterns; PD-1, programmed cell death-1/CD279; SC, subcutaneous; Tregs, regulatory T cells; TLR, toll-like receptors; TAA, tumor-associated Ag; TIL, tumor infiltrating lymphocytes. 
(neoAgs) which are recognized by the immune system (4); of tumor infiltration by specific immune populations and their clinical correlation (5); and of tumor immunoediting including immune escape strategies (6). More recently, the discovery of multiple immune checkpoint mechanisms, either stimulatory or inhibitory pathways of the immune system, which can be targeted with monoclonal antibodies (mAbs), has burst into intense clinical research. In particular, immune checkpoint blockade (ICKB) with mAbs immunotherapy has proved for the first time to improve overall survival (OS) of CM metastatic patients (7). Nowadays, immunotherapeutic approaches including ICKB with $\mathrm{mAbs}$ is the fourth cancer treatment modality along with surgery, radiotherapy, and chemotherapy/targeted therapy. The use of ICKB has expanded beyond CM and these therapies are now approved for the treatment of several metastatic tumors, including renal cell carcinoma, non-small-cell lung carcinoma, squamous cell carcinoma of the head and neck, urothelial carcinoma, and Hodgkin lymphoma (www.fda.gov/drugs).

The inhibitory immune checkpoint molecules act as physiological brakes that prevent potentially harmful immune responses and autoimmunity. Cytotoxic T-lymphocyte antigen 4 (CTLA-4) is constitutively expressed in regulatory T cells (Tregs) but is only upregulated in T-cells after activation. Physiologically, CTLA-4 transmits an inhibitory signal to T cells to shut down immune responses by interaction with CD80 and CD86 molecules, which are expressed at the surface of Ag-presenting cells (APCs) such as dendritic cells (DCs) and macrophages; CTLA-4 also contributes to the inhibitory function of Tregs (8). Ipilimumab (Bristol-Myers Squibb) targets CTLA-4, blocking the inhibitory signal, unleashing cytotoxic $\mathrm{T}$ cells to eliminate the cancer cells (7). Another inhibitory immune-checkpoint that has been extensively targeted with $\mathrm{mAbs}$ is the axis programmed cell death-1/CD279 (PD-1) and their ligands PD-L1 (B7-H1/ CD274) and PD-L2 (B7-DC/CD273) (9). PD-1 is expressed on the membrane of activated T lymphocytes; PD-L1 and PD-L2 are expressed in APCs and also in some tumor cells. PD-1 and PD-L1/PD-L2 binding induce a coinhibitory signal that limits the development of the T-cell response. Several blocking mAbs targeting PD-1 are currently indicated to treat different tumors, such as nivolumab (Bristol-Myers Squibb) (10) and pembrolizumab (Merck Sharp \& Dohme) (11). Accordingly, there are mAbs targeting PD-L1, such as atezolizumab (Roche), avelumab (EMD, Serono), and durvalumab (Astra Zeneca). Blocking of CTLA-4 molecule would affect the initial priming phase while targeting the PD-1/PD-L1 axis would interfere more profoundly with the effector phase of the anti-immune response. Although ICKB has shown to potentiate long-lasting antitumor immune response in the metastatic setting, about only $30 \%$ of patients achieve durable responses to ICKB with $\mathrm{mAbs}$, thus intense research is ongoing to unravel the mechanisms involved in both primary and acquired $\mathrm{ICKB}$ resistance.

Now that ICKB has proven to induce clinical responses for several tumor pathologies, it is currently being investigated in combination with other immunomodulatory strategies in clinical trials, in an attempt to improve antitumor immune responses. ICKB can be combined with antagonists of immunosuppressive molecules or different immunostimulatory treatments, such as active tumor vaccines, administration of cytokines, tumor-specific mAbs, and adoptive cell therapy (ACT). As shown in Figure 1, future immunotherapy can be seen from an integrative point of view, allowing the combination of different approaches that target both the tumor cells and the immune microenvironment, with impact in the systemic immune status. In this review, we have selected several examples of such combinatory strategies that are currently being investigated in clinical studies to discuss the rationale and potential results (www.clinicaltrials.gov) (Tables 1-3). Most of these trials are in the initial phases (I-II) and are directed toward advanced metastatic tumor patients including $\mathrm{CM}$, mainly to optimize dose regimens and observe safety, side effects, and initial response in patients, including potential immunogenicity and antitumor immune response.

\section{CLINICAL TRIALS}

\section{ICKB Combined with Immunostimulatory Strategies}

\section{Vaccines}

Therapeutic vaccines are under investigation but still have shown only limited clinical benefit for patients with CM and other tumors. The rationale of therapeutic vaccination is to boost the patient's immune system to induce a pro-inflammatory $\mathrm{T}_{\mathrm{H}} 1$ immune response targeting both shared common tumor Ags and patient-specific neoAgs generated by somatic mutations in a personalized fashion. Vaccines can be prepared as peptides, tumor lysates, or irradiated whole tumor cells, administered with adjuvants to potentiate the immune response or as autologous DCs loaded with the tumor-Ag source.

The Phase III pivotal study that allowed FDA approval of ipilimumab to treat unresectable Stage III-IV melanoma patients was in fact designed to determine the safety and efficacy of ipilimumab in combination with BMS-734019 vaccine, a tumor-associated Ag (TAA) gp100-peptide vaccine, versus vaccine or ipilimumab alone (NCT00094653) (7). The main results of that study were that ipilimumab, with or without a vaccine, in comparison to vaccine alone, improved OS of metastatic CM patients. Severe adverse events were observed but most of them were reversible and manageable. In 2015, a pooled analysis was performed of long-term survival data of 1861 patients from Phase II and III studies (NCT00032045, NCT00058279, NCT00077532, NCT00094653, NCT00135408, NCT00261365, NCT00289627, NCT00289640, NCT00324155, and NCT00623766), some of them including combined vaccination with peptides, the majority of patients receiving the $3 \mathrm{mg} / \mathrm{kg}$ regimen. Also, data from additional 2,985 patients from an expanded access program were analyzed. A plateau in the survival curve was observed, beginning at approximately 3 years, which was independent of prior therapy or ipilimumab dose, supporting the impact of ipilimumab in long-term survival for advanced CM patients (12).

Recent combination trials of ICKB with peptide vaccines are shown in Table 1. 6MHP, a melanoma vaccine comprised of 6 MHC-II-restricted helper peptides administered subcutaneous (SC) and intradermally (ID) as water-in-oil emulsions with Montanide ISA-51, in combination with pembrolizumab 


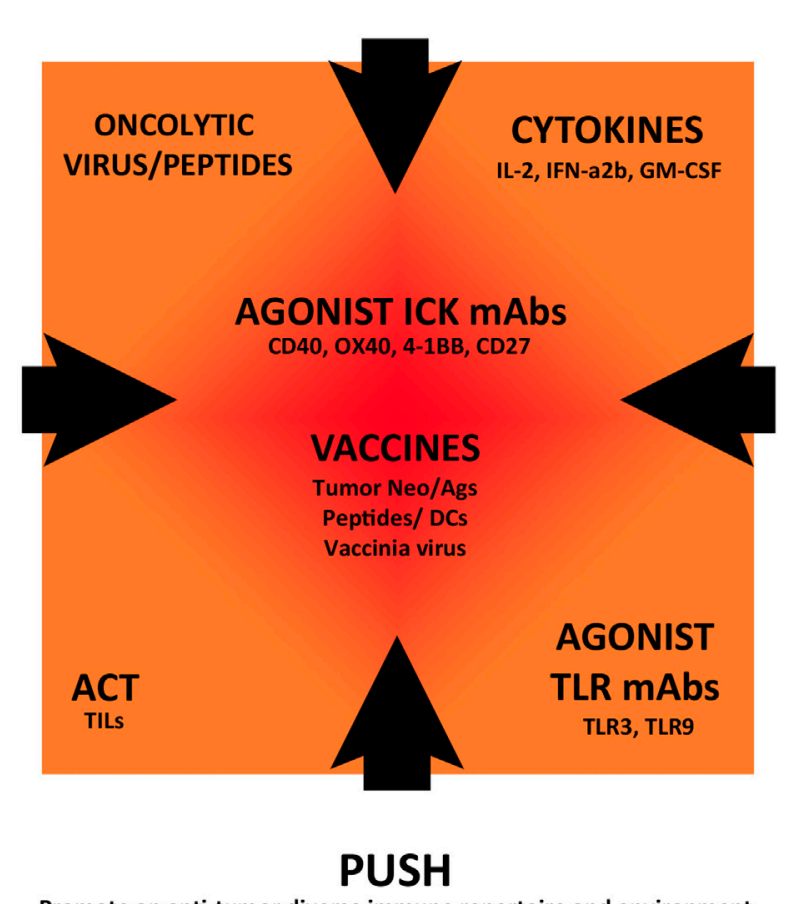

Promote an anti-tumor diverse immune repertoire and environment

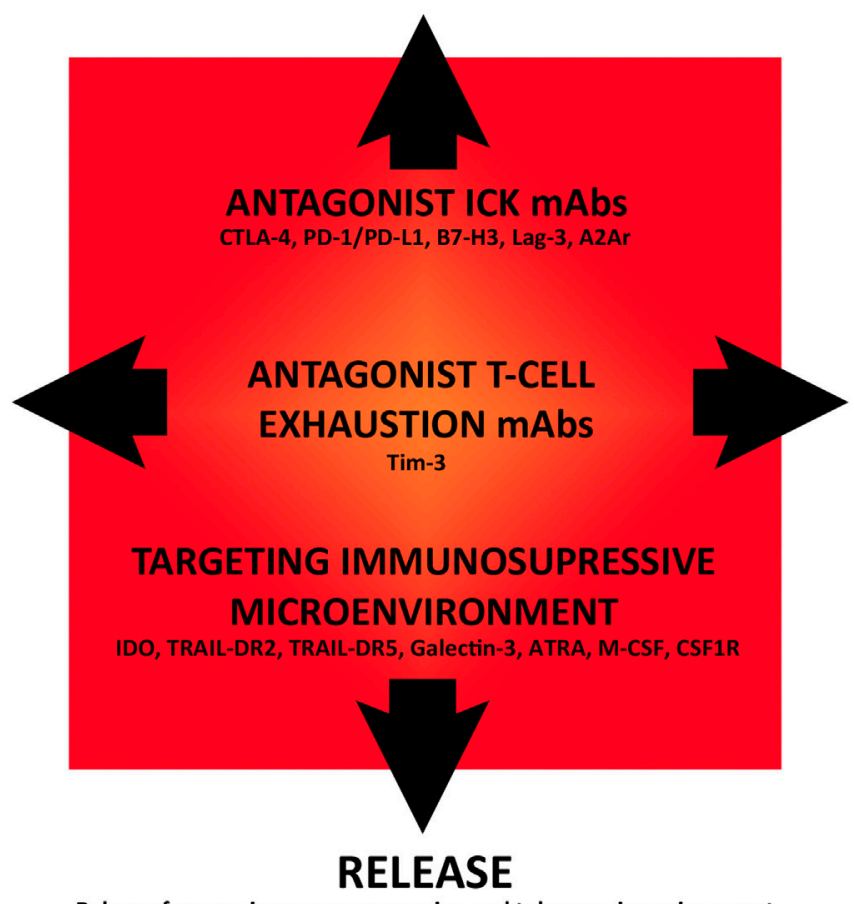

Release from an immune suppressive and tolerogenic environment

FIGURE 1 | Immunomodulatory monoclonal antibodies and combination strategies in cutaneous melanoma immunotherapy. Different immunotherapeutic strategies are currently being assessed in combination in clinical trials that either "push" tumor immunoreactivity or "release" from inhibitory immune-regulatory mechanisms, fostering this way an antitumor immune response.

(NCT02515227) or ipilimumab (NCT02385669), is under investigation. NCT03047928 trial will combine nivolumab with a peptide vaccine consisting of PD-L1 and indoleamine 2,3-dioxygenase (IDO) peptides. T-cell reactivity against PD-L1 and IDO in the tumor microenvironment and in the peripheral blood of CM patients with cytotoxic activity has been reported (13). Thus boosting specific $\mathrm{T}$ cells that recognize immune regulatory proteins such as IDO and PD-L1 may directly modulate immune regulation. In the protocol, patients will be treated with nivolumab every second week as long as there is a clinical benefit. The PD-L1/ IDO peptide vaccine is given from the start of nivolumab and every second week for the first six vaccines and thereafter every fourth week up to 1 year. NCT01176461 tested the side effects of an investigational vaccine consisting of gp100280-288 and NY-ESO-1157-165 MHC-I peptides and adjuvant Montanide ISA-51-VG, combined with escalating doses of antagonist PD-1 mAb BMS-936558. A cohort of patients will not receive the vaccine. Phase I trial results indicated that combination was well tolerated and induced responses lasting up to 140 weeks (14).

Another interesting strategy is being tested in NCT02897765, combining nivolumab with NEO-PV-01, a personalized vaccine therapy designed to target mutated proteins which are present uniquely on an individual's tumor neoAgs, with poly-ICLC as the adjuvant. Patients will receive $240 \mathrm{mg}$ IV nivolumab every 2 weeks and those patients who have not achieved a complete response to nivolumab alone at week 12 will receive NEO-PV-01+ adjuvant SC, in up to four distinct sites while continuing therapy with nivolumab. The study will monitor side effects and Ag-specificity in peripheral $\mathrm{CD}^{+}$and $\mathrm{CD}^{+} \mathrm{T}$ cell responses and tumor biopsies, which will be assessed after treatment.

NCT01302496 studies ipilimumab combined with TriMix vaccine. The TriMix-DC vaccine is a DC-based vaccine that can induce a T-cell repertoire that recognizes the TAA MAGE-A3, MAGE-C2, tyrosinase, and gp100 in an HLA-restricted way, in unresectable stage III-IV melanoma patients $(15,16)$. To prepare TriMix-Dc vaccine, autologous DCs are coelectroporated with TriMix mRNA (a combination of CD40L, caTLR4, and CD70 encoding mRNA) in combination with one of four TAA mRNAs linked to an HLA-II targeting signal. After electroporation, the four different TriMixDC-MEL cellular constituents (i.e., DCs expressing one of the four Ags) are mixed at equal ratios and cryopreserved until vaccination. The study is complete but results are still unpublished.

NCT02432963 proposes another combination strategy with ICKB and vaccines, testing a modified Vaccinia Virus Ankara Vaccine expressing tumor protein p53 (p53MVA Vaccine) in combination with pembrolizumab, in patients with tumors with overexpression or mutation of $\mathrm{p} 53$. Immune monitoring in peripheral blood samples obtained through the protocol will analyze T-cell reactivity to $\mathrm{p} 53$, myeloid-derived suppressor cell (MDSC) and Tregs immunosuppressive populations, and other selected subsets including PD- $1^{+}, \mathrm{PDL}-1^{+}$, and PDL- ${ }^{+}$cells.

Finally, in a Phase I/II study (NCT02275416), ipilimumab ( $3 \mathrm{mg} / \mathrm{kg}$, every 3 weeks for a total of four doses) in combination 
TABLE 1 | Clinical trials combining immune checkpoint blockade with immunostimulatory strategies.

\begin{tabular}{|c|c|c|c|c|c|}
\hline $\begin{array}{l}\text { Trial identifier/ } \\
\text { study phase/ } \\
\text { status }\end{array}$ & Combination therapy & $\begin{array}{l}\text { Patient } \\
\text { condition }\end{array}$ & Sponsor & Official study title & Study design \\
\hline $\begin{array}{l}\text { NCT02515227 } \\
\text { Phase I/II } \\
\text { (recruiting, 2015) }\end{array}$ & $\begin{array}{l}\text { - Pembrolizumab } \\
\text { (antagonist PD-1, } \\
\text { mAb) • 6MHP peptide } \\
\text { vaccine (6 class II } \\
\text { MHC-restricted helper } \\
\text { peptides) }\end{array}$ & $\begin{array}{l}\text { Metastatic } \\
\text { melanoma } \\
(\mathrm{MM})\end{array}$ & Craig L Slingluff, Jr & $\begin{array}{l}\text { A trial to evaluate the safety, } \\
\text { immunogenicity, and clinical activity } \\
\text { of a helper peptide vaccine plus } \\
\text { PD-1 blockade }\end{array}$ & $\begin{array}{l}\text { 6MHP vaccine ( } 200 \text { mg/each six peptides), } \\
\text { mixed } 1 / 1 \text { with Montanide ISA-51, will be } \\
\text { administered intradermally (ID)/ } \\
\text { subcutaneous (SC) at days } 1,8,15, \\
\text { 43, 64, and } 85 . \text { Pembrolizumab } 200 \text { mg } \\
\text { intravenous (IV)/3 weeks/2 years }\end{array}$ \\
\hline $\begin{array}{l}\text { NCT02385669 } \\
\text { Phase I/II } \\
\text { (recruiting, 2015) }\end{array}$ & $\begin{array}{l}\text { - Ipilimumab [antagonist } \\
(\mathrm{CTLA}-4) \mathrm{mAb} \cdot \bullet \mathrm{MHP} \\
\text { peptide vaccine }(6 \text { class } \\
\text { II MHC-restricted helper } \\
\text { peptides) }\end{array}$ & MM & Craig L Slingluff, Jr & $\begin{array}{l}\text { A Phase I/II trial to evaluate the } \\
\text { safety, immunogenicity, and } \\
\text { clinical activity of a helper peptide } \\
\text { vaccine plus CTLA- } 4 \text { blockade } \\
\text { in advanced melanoma (Mel62; } \\
6 \text { PAC) }\end{array}$ & $\begin{array}{l}\text { 6MHP vaccine ( } 200 \mathrm{mg} / \text { each six peptides), } \\
\text { mixed } 1 / 1 \text { with Montanide ISA-51, will be } \\
\text { administered ID/SC at days } 1,8,15,43,64 \text {, } \\
\text { and } 85 . \text { Ipilimumab will be administered } 3 \mathrm{mg} / \mathrm{kg} \\
\text { IV/3 weeks/four doses }\end{array}$ \\
\hline $\begin{array}{l}\text { NCT03047928 } \\
\text { Phase I/II } \\
\text { (recruiting, 2017) }\end{array}$ & $\begin{array}{l}\text { - Nivolumab (antagonist } \\
\text { PD-1 mAb) • } \\
\text { PD-L1/indoleamine } \\
\text { 2,3-dioxygenase (IDO) } \\
\text { peptide vaccine }\end{array}$ & $\mathrm{MM}$ & Inge Marie Svane & $\begin{array}{l}\text { Combination therapy with } \\
\text { nivolumab and PD-L1/IDO peptide } \\
\text { vaccine to patients with MM }\end{array}$ & $\begin{array}{l}\text { - Patients receive nivolumab IV } 3 \text { mg/ } \\
\text { kg biweekly until progression. } \bullet \text { Vaccine } \\
\text { administration starts concomitantly with } \\
\text { nivolumab, biweekly six times, then every fourth } \\
\text { week up } 1 \text { year. A vaccine consists of } 100 \mu \mathrm{g} \\
\text { IDO peptide, } 100 \mu \mathrm{g} \text { PD-L1 peptide, and } 500 \mu \mathrm{l} \\
\text { Montanide as adjuvant. } \bullet \text { Patients who complete } \\
\text { all vaccines will continue nivolumab treatment } \\
\text { after standard guidelines }\end{array}$ \\
\hline $\begin{array}{l}\text { NCT01176461 } \\
\text { Phase I } \\
\text { (ongoing, not } \\
\text { recruiting, 2010) }\end{array}$ & $\begin{array}{l}\text { - BMS-936558: } \\
\text { antagonist PD-1 mAb • } \\
\text { Peptide vaccine: MART- } \\
\text { 1, NY-ESO-1, gp100 • } \\
\text { Adjuvant: Montanide ISA } \\
51 \text { VG }\end{array}$ & $\mathrm{MM}$ & $\begin{array}{l}\text { H. Lee Moffitt } \\
\text { Cancer Center, } \\
\text { National Cancer } \\
\text { Institute (NCl), } \\
\text { Bristol-Myers } \\
\text { Squibb, Medarex }\end{array}$ & $\begin{array}{l}\text { A pilot trial of a vaccine combining } \\
\text { multiple class I peptides and } \\
\text { Montanide ISA } 51 \text { VG with } \\
\text { escalating doses of anti-PD-1 } \\
\text { antibody BMS-936558 for patients } \\
\text { with unresectable Stages III/IV } \\
\text { melanoma }\end{array}$ & $\begin{array}{l}\text { - Arm 1: Phase I dose escalation cohort. } \\
\text { Six doses of BMS-936558 and six peptide } \\
\text { vaccines administered/2 weeks/12 weeks. • } \\
\text { Arm comparator: BMS-936558 without peptide } \\
\text { vaccine }\end{array}$ \\
\hline $\begin{array}{l}\text { NCT02897765 } \\
\text { Phase I } \\
\text { (recruiting, 2016) }\end{array}$ & $\begin{array}{l}\bullet \text { NEO-PV-01 } \\
\text { personalized vaccine } \bullet \\
\text { Nivolumab • Poly-ICLC }\end{array}$ & $\begin{array}{l}\text { Metastatic } \\
\text { tumors } \\
\text { including } \\
\text { MM }\end{array}$ & $\begin{array}{l}\text { Neon Therapeutic } \\
\text { Inc., Bristol-Myers } \\
\text { Squibb }\end{array}$ & $\begin{array}{l}\text { An open-label, Phase IB study } \\
\text { of NEO-PV-01 + adjuvant with } \\
\text { nivolumab in patients with } \\
\text { melanoma, non-small-cell lung } \\
\text { carcinoma or transitional cell } \\
\text { carcinoma of the bladder }\end{array}$ & $\begin{array}{l}\text { - Nivolumab } 240 \text { mg IV infusion/2 weeks. } \\
\text { Patients who have not achieved a CR to } \\
\text { nivolumab alone at week } 12 \text { will receive } \\
\text { NEO-PV-01 + adjuvant SC (one vial of pooled } \\
\text { peptides per injection site) in up to four distinct } \\
\text { sites (each extremity or flanks) while continuing } \\
\text { therapy with nivolumab }\end{array}$ \\
\hline $\begin{array}{l}\text { NCT01302496 } \\
\text { Phase II } \\
\text { (completed, } \\
\text { 2017) }\end{array}$ & $\begin{array}{l}\text { - TriMix-DC vaccine } \\
\text { ipilimumab (antagonist } \\
\text { CTLA-4 mAb) }\end{array}$ & MM & $\begin{array}{l}\text { Bart Neyns, Vrije } \\
\text { Universiteit Brussel }\end{array}$ & $\begin{array}{l}\text { A two-stage Phase II study of } \\
\text { autologous TriMix-DC therapeutic } \\
\text { vaccine in combination with } \\
\text { ipilimumab in patients with } \\
\text { previously treated unresectable } \\
\text { stage III or IV melanoma }\end{array}$ & $\begin{array}{l}\text { Patients will receive five TriMix-DC doses. All } \\
\text { administrations but first will be preceded by } \\
\text { ipilimumab } 10 \mathrm{mg} / \mathrm{kg} \text {. NED patients will be } \\
\text { offered ipilimumab maintenance }(10 \mathrm{mg} / \mathrm{kg} \\
\text { q12wks) }\end{array}$ \\
\hline $\begin{array}{l}\text { NCT02432963 } \\
\text { Phase I } \\
\text { (recruiting, 2015) }\end{array}$ & $\begin{array}{l}\text { - Pembrolizumab } \\
\text { (antagonist PD-1 mAb) } \\
\text { - modified vaccinia } \\
\text { virus ankara vaccine } \\
\text { expressing p53 }\end{array}$ & $\begin{array}{l}\text { Metastatic } \\
\text { tumors } \\
\text { including } \\
\text { MM }\end{array}$ & $\begin{array}{l}\text { City of Hope } \\
\text { Medical Center }\end{array}$ & $\begin{array}{l}\text { A Phase I study of a p53MVA } \\
\text { vaccine in combination with } \\
\text { pembrolizumab }\end{array}$ & $\begin{array}{l}\text { Patients receive pembrolizumab IV followed by } \\
\text { p53MVA Vaccine at least } 30 \text { min later once in } \\
\text { weeks } 1,4,7\end{array}$ \\
\hline $\begin{array}{l}\text { NCT02275416 } \\
\text { Phase I/II } \\
\text { (recruiting, 2014) }\end{array}$ & $\begin{array}{l}- \text { Ipilimumab (antagonist } \\
\text { CTLA-4 mAbs). } • \\
\text { Biological: UV1 vaccine } \\
\text { (peptide based-vaccine } \\
\text { directed to hTERT) • } \\
\text { Biological: GM-CSF }\end{array}$ & MM & Ultimovacs AS & $\begin{array}{l}\text { Safety of UV1 vaccination in } \\
\text { combination with ipilimumab in } \\
\text { patients with unresectable or } \\
\text { metastatic malignant melanoma }\end{array}$ & $\begin{array}{l}\text { - Ipilimumab }(3 \mathrm{mg} / \mathrm{kg}) / 3 \text { weeks/four doses. } \\
\text { UV1 vaccine } 300 \mathrm{\mu g} \text { plus GM-CSF } 75 \mu \mathrm{gg} \text { ID } \\
\text { in the lower abdomen every } 4 \text { weeks up to } \\
28 \text { weeks, at weeks } 36 \text { and } 48\end{array}$ \\
\hline $\begin{array}{l}\text { NCT00058279 } \\
\text { Phase I/II } \\
\text { (completed, } \\
\text { 2006) }\end{array}$ & $\begin{array}{l}\text { - Ipilimumab (antagonist } \\
\text { CTLA-4 mAb) • } \\
\text { Aldesleukin (IL-2) }\end{array}$ & $\begin{array}{l}\text { Intraocular/ } \\
\text { skin MM }\end{array}$ & $\mathrm{NCl}$ & $\begin{array}{l}\text { MDX-CTLA4 combined with IL-2 } \\
\text { for patients with MM }\end{array}$ & $\begin{array}{l}\text { Patients received } 3.0 \mathrm{mg} / \mathrm{kg} \text { ipilimumab every } \\
3 \text { weeks and IL-2 (720,000 IU/kg every } 8 \mathrm{~h} \text { to a } \\
\text { maximum of } 15 \text { doses) }\end{array}$ \\
\hline
\end{tabular}


TABLE 1 | Continued

\begin{tabular}{|c|c|c|c|c|c|}
\hline $\begin{array}{l}\text { Trial identifier/ } \\
\text { study phase/ } \\
\text { status }\end{array}$ & Combination therapy & $\begin{array}{l}\text { Patient } \\
\text { condition }\end{array}$ & Sponsor & Official study title & Study design \\
\hline $\begin{array}{l}\text { NCT02983045 } \\
\text { Phase I/II } \\
\text { (recruiting, 2016) }\end{array}$ & $\begin{array}{l}\text { - Nivolumab (antagonist } \\
\text { PD-1 mAb) • NKTR-214 } \\
(\text { IL-2) }\end{array}$ & $\begin{array}{l}\text { Metastatic } \\
\text { tumors } \\
\text { including } \\
\text { MM }\end{array}$ & $\begin{array}{l}\text { Nektar } \\
\text { Therapeutics }\end{array}$ & $\begin{array}{l}\text { A Phase } 1 / 2 \text {, open-label, } \\
\text { multicenter, dose escalation and } \\
\text { dose expansion study of NKTR- } \\
214 \text { and nivolumab in patients } \\
\text { with select locally advanced or } \\
\text { metastatic solid tumor malignancies }\end{array}$ & $\begin{array}{l}\text { - Phase 1: patients will receive NKTR-214 } \\
\text { every 14/21 days, in combination with } \\
240 \mathrm{mg} / 360 \mathrm{mg} \text { nivolumab every } 14 / 21 \text { days. } \\
\text { Phase } 2 \text { : additional patient cohorts will be dosed } \\
\text { at the recommended Phase } 2 \text { dose/schedule } \\
\text { of NKTR-214 and nivolumab (as determined by } \\
\text { Phase } 1 \text { of the trial) }\end{array}$ \\
\hline $\begin{array}{l}\text { NCT02748564 } \\
\text { Phase I/II } \\
\text { (recruiting, 2017) }\end{array}$ & $\begin{array}{l}\text { - Pembrolizumab } \\
\text { (antagonist PD-1 mAb) • } \\
\text { aldeleuskin (IL-2) }\end{array}$ & $\begin{array}{l}\text { Metastatic } \\
\text { tumors } \\
\text { including } \\
\text { MM }\end{array}$ & $\begin{array}{l}\text { Rutgers, The State } \\
\text { University of New } \\
\text { Jersey }\end{array}$ & $\begin{array}{l}\text { A Phase } 1 \mathrm{~b} / \mathrm{ll} \text { trial of interleukin-2 in } \\
\text { combination with pembrolizumab } \\
\text { for patients with unresectable or } \\
\text { MM }\end{array}$ & $\begin{array}{l}\text { Patients will receive pembrolizumab IV every } \\
3 \text { weeks and aldesleukin IV every } 8 \text { h for up to } \\
14 \text { doses at weeks } 4,7,16,19,28 \text {, and } 31 \text { in } \\
\text { the absence of progression/toxicity }\end{array}$ \\
\hline $\begin{array}{l}\text { NCT01608594 } \\
\text { Phase I } \\
\text { (ongoing, not- } \\
\text { recruiting, 2013) }\end{array}$ & $\begin{array}{l}\bullet \text { Ipilimumab (antagonist } \\
\text { CTLA-4 mAb) } \bullet \mathrm{HDI} \\
\text { (high-dose IFN-a2b) }\end{array}$ & MM & Ahmad Tarhini & $\begin{array}{l}\text { Neoadjuvant combination } \\
\text { biotherapy with ipilimumab ( } 3 \text { or } \\
10 \mathrm{mg} / \mathrm{kg} \text { ) and high-dose IFN- } \alpha 2 \mathrm{~B} \\
\text { in patients with locally/regionally } \\
\text { advanced/recurrent melanoma: a } \\
\text { randomized safety, efficacy and } \\
\text { biomarker study }\end{array}$ & $\begin{array}{l}\text { Patients will receive IFN-a2b at } 20 \mathrm{MU} / \mathrm{m}^{2} / \text { day } \\
\text { IV for } 5 \text { consecutive days/4 weeks, followed } \\
\text { by } 10 \mathrm{MU} / \mathrm{m}^{2} / \text { day SC thrice a week/2 weeks, } \\
\text { followed by definitive surgery. After recovery, } \\
\text { IFN-a2b will be resumed at } 10 \mathrm{MU} / \mathrm{m}^{2} / \text { day SC, } \\
\text { thrice a week/46 additional weeks. IFN-a2b will } \\
\text { be given concurrently with ipilimumab at } 3 \text { or } \\
10 \mathrm{mg} / \mathrm{kg}\end{array}$ \\
\hline $\begin{array}{l}\text { NCT01708941 } \\
\text { Phase II } \\
\text { (ongoing, not- } \\
\text { recruiting, 2013) }\end{array}$ & $\begin{array}{l}\bullet \text { Ipilimumab (antagonist } \\
\text { CTLA-4 mAb) • HDI } \\
\text { (high-dose IFN-a2b) }\end{array}$ & $\mathrm{MM}$ & $\mathrm{NCl}$ & $\begin{array}{l}\text { A randomized Phase } \| \text { study of } \\
\text { ipilimumab at } 3 \text { or } 10 \mathrm{mg} / \mathrm{kg} \text { alone } \\
\text { or in combination with high-dose } \\
\text { interferon-alpha in advanced } \\
\text { melanoma }\end{array}$ & $\begin{array}{l}\text { There are different cohorts where patients either } \\
\text { receive higher dose ipilimumab, higher dose } \\
\text { ipilimumab plus HDI, lower dose ipilimumab, and } \\
\text { lower dose ipilimumab plus HDI }\end{array}$ \\
\hline $\begin{array}{l}\text { NCT02112032 } \\
\text { Phase I } \\
\text { (recruiting, 2014) }\end{array}$ & $\begin{array}{l}-\mathrm{MK}-3475 \text { (antagonist } \\
\text { PD-1 mAb) } \\
\text { PegIFN-a2b }\end{array}$ & MM & $\begin{array}{l}\text { Hassane M. } \\
\text { Zarour, MD }\end{array}$ & $\begin{array}{l}\text { Phase } 1 \text { study of anti-PD-1 } \\
\text { antibody MK-3475 and PeglFNa- } \\
\text { 2b for advanced melanoma }\end{array}$ & $\begin{array}{l}2 \text { years treatment with MK-3475: } 2 \text { mg/kg every } \\
3 \text { weeks IV and PegIFN-a2b: } 1 \text { } \mu \mathrm{g} / \mathrm{kg} \text { every } \\
\text { week SC }\end{array}$ \\
\hline $\begin{array}{l}\text { NCT02339324 } \\
\text { Phase I } \\
\text { (recruiting, 2015) }\end{array}$ & $\begin{array}{l}\text { - Pembrolizumab } \\
\text { (antagonist PD-1 mAb) } \\
\text { - HDI }\end{array}$ & MM & $\begin{array}{l}\text { University of } \\
\text { Pittsburgh }\end{array}$ & $\begin{array}{l}\text { Neoadjuvant combination } \\
\text { biotherapy with pembrolizumab } \\
\text { and high dose IFN-alfa2b in } \\
\text { patients with locally/regionally } \\
\text { advanced/recurrent melanoma: } \\
\text { safety, efficacy and biomarker study }\end{array}$ & $\begin{array}{l}\text { - Induction phase (first } 6 \text { weeks): } \\
\text { pembrolizumab IV for two doses/4 weeks } \\
\text { concurrently with HDI IV × } 5 \text { consecutive days/ } \\
\text { week/4 weeks, followed by SC every other } \\
\text { day } 3 \times \text { each week/2 weeks. • Surgery phase } \\
\text { (week 6-8). • Maintenance phase (following } \\
\text { recovery from surgery): pembrolizumab IV } \\
\text { infusion/3 weeks given concurrently with HDI SC } \\
\text { every week/46 additional weeks }\end{array}$ \\
\hline $\begin{array}{l}\text { NCT02174172 } \\
\text { Phase I } \\
\text { (recruiting, 2014) }\end{array}$ & $\begin{array}{l}\text { - Atezolizumab } \\
\text { (antagonist PD-L1 } \\
\text { mAb) • bevacizumab } \\
\text { (antagonist VEGF } \\
\text { mAb)• ipilimumab } \\
\text { (antagonist CTLA-4 } \\
\text { mAb) • obinutuzumab } \\
\text { (antagonist CD20 mAb) } \\
\text { - IFNa2b } \bullet \text { Peg-IFNa2b }\end{array}$ & $\begin{array}{l}\text { Metastatic } \\
\text { tumors } \\
\text { including } \\
\text { MM }\end{array}$ & $\begin{array}{l}\text { Hoffmann-La } \\
\text { Roche }\end{array}$ & $\begin{array}{l}\text { A Phase lb study of the safety and } \\
\text { pharmacology of atezolizumab } \\
\text { (anti-PD-L1 antibody) administered } \\
\text { with ipilimumab, interferon-alpha, or } \\
\text { other immune-modulating therapies } \\
\text { in patients with locally advanced or } \\
\text { metastatic solid tumors }\end{array}$ & $\begin{array}{l}\bullet \text { Arm A: atezolizumab with ipilimumab; } \\
\text { Arm B: atezolizumab with IFN-A2b; • Arm } \\
\text { C: Atezolizumab With PEG-IFN-A2b; • Arm } \\
\text { D: atezolizumab with PEG-IFN-A2b and } \\
\text { bevacizumab; • Arm E: atezolizumab with } \\
\text { obinutuzumab }\end{array}$ \\
\hline $\begin{array}{l}\text { NCT02009397 } \\
\text { Phase I/II } \\
\text { (recruiting, 2012) }\end{array}$ & $\begin{array}{l}\text { - Ipilimumab (antagonist } \\
\text { CTLA-4 mAb) • } \\
\text { rhuGM-CSF }\end{array}$ & MM & $\begin{array}{l}\text { J Graham Brown } \\
\text { Cancer Center }\end{array}$ & $\begin{array}{l}\text { A Phase I/II open-label study } \\
\text { of ipilimumab and GM-CSF } \\
\text { administered to unresectable } \\
\text { Stage IIIC and Stage IV melanoma } \\
\text { patients }\end{array}$ & $\begin{array}{l}\text { IV ipilimumab followed by SC GM-CSF, for up to } \\
\text { four cycles }\end{array}$ \\
\hline $\begin{array}{l}\text { NCT02652455 } \\
\text { Phase I } \\
\text { (recruiting, 2016) }\end{array}$ & $\begin{array}{l}\bullet \text { Nivolumab }(\mathrm{PD}-1 \\
\text { antagonist mAb) } \bullet \\
\text { autologous tumor } \\
\text { infiltrating lymphocyte } \\
(\mathrm{TIL}) \bullet \text { CD137 } \\
\text { agonist mAb } \bullet \\
\text { cyclophosphamide } \bullet \\
\text { fludarabine } \bullet \mathrm{IL}-2\end{array}$ & MM & $\begin{array}{l}\text { H. Lee Moffitt } \\
\text { Cancer Center and } \\
\text { Research Institute }\end{array}$ & $\begin{array}{l}\text { A pilot clinical trial combining PD-1 } \\
\text { blockade, CD137 agonism and } \\
\text { adoptive cell therapy for MM }\end{array}$ & $\begin{array}{l}\text { - Patients will receive treatment with } \\
\text { nivolumab prior to tumor removal for TIL } \\
\text { growth. • Surgery and TIL growth ex vivo. } \\
\text { - Patients lymphodepleting chemotherapy } \\
\text { with cyclophosphamide and fludarabine; TIL } \\
\text { infusion; interleukin-2 treatment. • The first six } \\
\text { participants will not receive nivolumab prior } \\
\text { treatment for comparison }\end{array}$ \\
\hline
\end{tabular}


TABLE 1 | Continued

\begin{tabular}{|c|c|c|c|c|c|}
\hline $\begin{array}{l}\text { Trial identifier/ } \\
\text { study phase/ } \\
\text { status }\end{array}$ & Combination therapy & $\begin{array}{l}\text { Patient } \\
\text { condition }\end{array}$ & Sponsor & Official study title & Study design \\
\hline $\begin{array}{l}\text { NCT01701674 } \\
\text { Phase I } \\
\text { (ongoing, not- } \\
\text { recruiting, 2012) }\end{array}$ & $\begin{array}{l}\bullet \text { Ipilimumab (CTLA-4 } \\
\text { antagonist mAb) } \bullet \\
\text { autologous TIL } \bullet \\
\text { cyclophosphamide } \bullet \\
\text { IL-2 }\end{array}$ & MM & $\begin{array}{l}\text { H. Lee Moffitt } \\
\text { Cancer Center and } \\
\text { Research Institute }\end{array}$ & $\begin{array}{l}\text { Costimulation with ipilimumab to } \\
\text { enhance lymphodepletion plus } \\
\text { adoptive cell transfer and high dose } \\
\text { IL-2 in patients with MM }\end{array}$ & $\begin{array}{l}\text { Combination of ipilimumab followed by } \\
\text { lymphodepletion with chemotherapy, TIL } \\
\text { infusion, and high dose IL-2 }\end{array}$ \\
\hline $\begin{array}{l}\text { NCT02027935 } \\
\text { Phase II } \\
\text { (recruiting, 2015) }\end{array}$ & $\begin{array}{l}\bullet \text { Ipilimumab (CTLA-4 } \\
\text { antagonist mAb) } \bullet \\
\text { autologous CD8 } \bullet \\
\text { cyclophosphamide } \bullet \\
\text { IL-2 }\end{array}$ & MM & $\begin{array}{l}\text { M.D. Anderson } \\
\text { Cancer Center }\end{array}$ & $\begin{array}{l}\text { Phase II study of cellular adoptive } \\
\text { immunotherapy using autologous } \\
\text { CD8+ antigen-specific T cells and } \\
\text { anti-CTLA4 for patients with MM }\end{array}$ & $\begin{array}{l}\bullet \text { Patients' leukapheresis to get and cultivate } \\
\text { CD8+ T cells. • Cyclophosphamide } 300 \text { mg/ } \\
\mathrm{m}^{2} \text { for lymphodepletion. } \bullet \text { IV Infusion of } 10^{10} \\
\text { T cells/m². } \bullet \text { IL-2 250,000 U/m² SC every } 12 \text { h } \\
\text { for } 14 \text { days. } \bullet \text { Ipilimumab } 3 \text { mg/kg IV } 24 \text { h } \\
\text { postinfusion and days } 22,43 \text {, and } 64\end{array}$ \\
\hline $\begin{array}{l}\text { NCT03123783 } \\
\text { Phase I/II } \\
\text { (recruiting, 2017) }\end{array}$ & $\begin{array}{l}\text { - Ipilimumab (antagonist } \\
\text { CTLA-4 mAb) • } \\
\text { APX005M (agonist CD40 } \\
\text { mAb) }\end{array}$ & MM & Apexigen, Inc. & $\begin{array}{l}\text { A study to evaluate the safety and } \\
\text { efficacy of the CD40 agonistic } \\
\text { antibody APX005M administered } \\
\text { in combination with nivolumab in } \\
\text { subjects with non-small-cell lung } \\
\text { cancer and subjects with MM }\end{array}$ & $\begin{array}{l}\text { Subjects will receive intravenously APX005M } \\
\text { in combination with nivolumab until disease } \\
\text { progression, unacceptable toxicity or death }\end{array}$ \\
\hline $\begin{array}{l}\text { NCT02706353 } \\
\text { Phase I/II } \\
\text { (recruiting, 2017) }\end{array}$ & $\begin{array}{l}\text { - Pembrolizumab } \\
\text { (antagonist PD-1 mAb) } \\
\text { - APX005M (agonist } \\
\text { CD40 mAb) }\end{array}$ & $\begin{array}{l}\text { Metastatic } \\
\text { tumors } \\
\text { including } \\
\text { MM }\end{array}$ & $\begin{array}{l}\text { M.D. Anderson } \\
\text { Cancer Center }\end{array}$ & $\begin{array}{l}\text { Phase I/II dose escalation and } \\
\text { cohort expansion of safety and } \\
\text { tolerability study of intratumoral } \\
\text { CD40 agonistic monoclonal } \\
\text { antibody APX005M in combination } \\
\text { with systemic pembrolizumab in } \\
\text { patients with MM }\end{array}$ & $\begin{array}{l}\text { - Dose escalation phase: initial dose APX005M } \\
0.1 \mathrm{mg} \text { injected into 1-3 tumors every } \\
3 \text { weeks/four doses up to maximum tolerated } \\
\text { dose (MTD). All participants will receive } \\
\text { pembrolizumab IV } 2 \text { mg/kg/3 weeks. • Dose } \\
\text { expansion phase: APX005M MTD, same of } \\
\text { pembrolizumab dosage }\end{array}$ \\
\hline $\begin{array}{l}\text { NCT02554812 } \\
\text { Phase II } \\
\text { (ongoing, 2015) }\end{array}$ & $\begin{array}{l}\bullet \text { Avelumab } \\
\text { (antagonist PD-L1 } \\
\text { mAb) • utomilumab } \\
\text { (agonist 41BB mAb) } \\
\text { PF-04518600 (agonist } \\
\text { OX-40 mAb) • PD } \\
\text { O360324 (neutralizing } \\
\text { M-CSF mAb) }\end{array}$ & $\begin{array}{l}\text { Metastatic } \\
\text { tumors } \\
\text { including } \\
\text { MM }\end{array}$ & Pfizer & $\begin{array}{l}\text { A Phase } 1 \mathrm{~b} / 2 \text { open-label study } \\
\text { to evaluate safety, clinical } \\
\text { activity, pharmacokinetics and } \\
\text { pharmacodynamics of avelumab } \\
\text { (msb0010718c) in combination } \\
\text { with other cancer immunotherapies } \\
\text { in patients with advanced } \\
\text { malignancies }\end{array}$ & $\begin{array}{l}\text { - Arm A: avelumab + utomilumab at } \\
\text { three different dose levels. • Arm B: dose } \\
\text { escalation PF-04518600 + avelumab. } \\
\text { - Arm C: dose escalation PD } \\
0360324 \text { + avelumab. • Arm D: dose escalation } \\
\text { utomilumab + PF-04518600 + avelumab. } \\
\text { Afterward, dose expansion } \\
\text { utomilumab + PF-04518600 + avelumab in } \\
\text { selected tumor types }\end{array}$ \\
\hline $\begin{array}{l}\text { NCT02643303 } \\
\text { Phase I/II } \\
\text { (recruiting, 2016) }\end{array}$ & $\begin{array}{l}- \text { Durvalumab } \\
\text { (antagonist PD-1 } \\
\text { mAb) } \bullet \text { Tremelimumab } \\
\text { (antagonist CTLA-4 } \\
\text { mAb) } \bullet \text { poly ICLC (TLR3 } \\
\text { agonist molecule) }\end{array}$ & $\begin{array}{l}\text { Metastatic } \\
\text { tumors } \\
\text { including } \\
\text { MM }\end{array}$ & $\begin{array}{l}\text { Ludwig Institute for } \\
\text { Cancer Research }\end{array}$ & $\begin{array}{l}\text { A Phase 1/2 study of in situ } \\
\text { vaccination with tremelimumab } \\
\text { and IV durvalumab (MEDI4736) } \\
\text { plus the toll-like receptor (TLR) } \\
\text { agonist PolylCLC in subjects with } \\
\text { advanced, measurable, biopsy- } \\
\text { accessible cancers }\end{array}$ & $\begin{array}{l}\text { - Phase I, cohort A: IV durvalumab + IT/ } \\
\text { IM polyICLC; cohort B: tremelimumab + IT/ } \\
\text { IM polyICLC; cohort C: } \\
\text { durvalumab + tremelimumab + IT/IM polyICLC. } \\
\text { Phase II: once the recommended combination } \\
\text { has been determined, subsequent subjects will } \\
\text { follow this dosing scheme }\end{array}$ \\
\hline $\begin{array}{l}\text { NCT02644967 } \\
\text { Phase I/II } \\
\text { (recruiting, 2015) }\end{array}$ & $\begin{array}{l}\text { - Ipilimumab (antagonist } \\
\text { CTLA-4 mAb) } \\
\text { pembrolizumab } \\
\text { (antagonist PD-1 mAb) } \\
\text { - IMO-2125 (TLR-9 } \\
\text { agonist) }\end{array}$ & MM & $\begin{array}{l}\text { Idera } \\
\text { Pharmaceuticals, } \\
\text { Inc. }\end{array}$ & $\begin{array}{l}\text { A Phase } 1 / 2 \text { study to assess the } \\
\text { safety and efficacy of intratumoral } \\
\text { IMO- } 2125 \text { in combination with } \\
\text { ipilimumab or pembrolizumab in } \\
\text { patients with MM }\end{array}$ & $\begin{array}{l}\text { - Cohort 1: IMO-2125 IT weekly, then } \\
\text { once/3 weeks. Ipilimumab IV at } 3 \text { mg/kg • } \\
\text { Cohort 2: IMO-2125, IMO-2125 IT weekly, then } \\
\text { once/3 weeks. Pembrolizumab, IV at } 2 \text { mg/ } \\
\text { kg/3 weeks }\end{array}$ \\
\hline $\begin{array}{l}\text { NCT02668770 } \\
\text { Phase I } \\
\text { (recruiting, 2016) }\end{array}$ & $\begin{array}{l}- \text { Ipilimumab (antagonist } \\
\text { CTLA-4 mab) } \\
\text { MGN1703 (TLR-9 } \\
\text { Agonist molecule) }\end{array}$ & $\begin{array}{l}\text { Metastatic } \\
\text { tumors } \\
\text { including } \\
\text { MM }\end{array}$ & $\begin{array}{l}\text { M.D. Anderson } \\
\text { Cancer Center }\end{array}$ & $\begin{array}{l}\text { A Phase I trial of ipilimumab } \\
\text { (immunotherapy) and MGN1703 } \\
\text { (TLR agonist) in patients with } \\
\text { advanced solid malignancies }\end{array}$ & $\begin{array}{l}\text { Dose escalation and expansion group of } \\
\text { MGN1703 doses, SC or ID ipilimumab will be } \\
\text { administrated } 3 \text { mg/kg/cycle } 8 \text { days following } \\
\text { MGN1703 administration }\end{array}$ \\
\hline $\begin{array}{l}\text { NCT02981303 } \\
\text { Phase II } \\
\text { (recruiting, 2016) }\end{array}$ & $\begin{array}{l}\text { - Pembrolizumab } \\
\text { (antagonist PD-1 mAb) • } \\
\text { Imprime PGG (PAMP) }\end{array}$ & $\begin{array}{l}\text { Metastatic } \\
\text { tumors } \\
\text { including } \\
\text { MM }\end{array}$ & Biothera & $\begin{array}{l}\text { A multicenter, open-label, Phase } \\
2 \text { study of imprime PGG and } \\
\text { pembrolizumab in subjects with } \\
\text { advanced melanoma failing front- } \\
\text { line treatment with checkpoint } \\
\text { inhibitors or triple negative } \\
\text { breast cancer failing front-line } \\
\text { chemotherapy for metastatic } \\
\text { disease }\end{array}$ & $\begin{array}{l}\text { - Imprime PGG IV } 4 \text { mg/kg on days } 1 \text {, 8, } \\
\text { 15/3-week treatment cycle. • Pembrolizumab IV } \\
200 \text { mg/kg following Imprime infusion }\end{array}$ \\
\hline
\end{tabular}


TABLE 2 | Clinical trials combining immune checkpoint blockade with targeting of immunosuppressive molecules.

\begin{tabular}{|c|c|c|c|c|c|}
\hline $\begin{array}{l}\text { Trial identifier/ } \\
\text { study phase/ } \\
\text { status }\end{array}$ & $\begin{array}{l}\text { Combination } \\
\text { therapy }\end{array}$ & $\begin{array}{l}\text { Patient } \\
\text { condition }\end{array}$ & Sponsor & Official study title & Study design \\
\hline $\begin{array}{l}\text { NCT02743819 } \\
\text { Phase II } \\
\text { (recruiting, 2016) }\end{array}$ & $\begin{array}{l}- \text { Pembrolizumab } \\
\text { (antagonist PD-1 } \\
\text { mAb) • ipilimumab } \\
\text { [antagonist } \\
(\mathrm{CTLA}-4) \mathrm{mAb} \text { ] }\end{array}$ & $\begin{array}{l}\text { Metastatic } \\
\text { melanoma } \\
(\mathrm{MM})\end{array}$ & $\begin{array}{l}\text { University of } \\
\text { Chicago }\end{array}$ & $\begin{array}{l}\text { Phase II study of pembrolizumab and } \\
\text { ipilimumab following initial anti-PD1/ } \\
\text { L1 antibody }\end{array}$ & $\begin{array}{l}\text { Pembrolizumab plus ipilimumab. } \bullet \text { Arm A: } \\
\text { progression on anti-PD1/L1 antibody } \bullet \text { Arm B: } \\
\text { stable disease more than } 24 \text { weeks or initial } \\
\text { response on anti-PD1/L1 antibody }\end{array}$ \\
\hline $\begin{array}{l}\text { NCT02381314 } \\
\text { Phase I } \\
\text { (recruiting, 2015) }\end{array}$ & $\begin{array}{l}\text { - Ipilimumab } \\
\text { (antagonist } \\
\text { CTLA-4 mab) • } \\
\text { enoblituzumab (B7- } \\
\text { H3 mAb) }\end{array}$ & $\begin{array}{l}\text { Metastatic } \\
\text { tumors } \\
\text { including } \\
\text { MM }\end{array}$ & MacroGenics & $\begin{array}{l}\text { A Phase 1, open-label, dose } \\
\text { escalation study of MGA271 in } \\
\text { combination with ipilimumab in } \\
\text { patients with melanoma, } \\
\text { non-small-cell lung cancer, and } \\
\text { other cancers }\end{array}$ & $\begin{array}{l}\text { Enoblituzumab will be administered IV once/ } \\
\text { week ( } 51 \text { doses) to determine maximum } \\
\text { tolerated dose (MTD) in combination with } \\
\text { ipilimumab, which is administered IV/3 weeks/ } \\
\text { four doses }\end{array}$ \\
\hline $\begin{array}{l}\text { NCT02460224 } \\
\text { Phase I/II } \\
\text { (recruiting, 2015) }\end{array}$ & $\begin{array}{l}\text { - PDR001 (antagonist } \\
\text { PD-1 mAb) • } \\
\text { LAG525 (antagonist } \\
\text { LAG-3 mAb) }\end{array}$ & $\begin{array}{l}\text { Metastatic } \\
\text { tumors } \\
\text { including } \\
\text { MM }\end{array}$ & $\begin{array}{l}\text { Novartis } \\
\text { Pharmaceuticals }\end{array}$ & $\begin{array}{l}\text { A Phase I/II, open label, multicenter } \\
\text { study of the safety and efficacy } \\
\text { of LAG525 single agent and } \\
\text { in combination with PDR001 } \\
\text { administered to patients with } \\
\text { advanced malignancies }\end{array}$ & $\begin{array}{l}\text { - Arm A: LAG525 single treatment arm. • Arm } \\
\text { B: LAG525 plus PDR001 combination arm. } \\
\text { - Arm C: LAG525 single treatment arm in } \\
\text { Japanese patients }\end{array}$ \\
\hline
\end{tabular}

\begin{tabular}{|c|c|c|c|c|c|}
\hline $\begin{array}{l}\text { NCT02655822 } \\
\text { Phase I } \\
\text { (recruiting, 2016) }\end{array}$ & $\begin{array}{l}\text { - } \mathrm{CPI}-444 \text { (blocking } \\
\text { adenosine-A2A } \\
\text { receptor inhibitor) } \\
\text { - atezolumab } \\
\text { (antagonist PD-L1 } \\
\text { mAb) }\end{array}$ & $\begin{array}{l}\text { Metastatic } \\
\text { tumors } \\
\text { including } \\
\text { MM }\end{array}$ & $\begin{array}{l}\text { Corvus } \\
\text { Pharmaceuticals, } \\
\text { Inc. }\end{array}$ & $\begin{array}{l}\text { A Phase 1/1b, open-label, } \\
\text { multicenter, repeat-dose, dose- } \\
\text { selection study of CPI- } 444 \text { as single } \\
\text { agent and in combination with } \\
\text { atezolizumab in patients with selected } \\
\text { incurable cancers }\end{array}$ & $\begin{array}{l}- \text { Cohort I: CPI-444 } 100 \text { mg orally twice daily for } \\
\text { the first } 14 \text { days/each } 28 \text {-day cycle. } \bullet \text { Cohort II: } \\
\text { CPI-444 } 100 \text { mg orally twice daily for } 28 \text { days/ } \\
\text { each } 28 \text {-day cycle. } \bullet \text { Cohort III: CPI-444 } \\
200 \text { mg orally once daily for the first } 14 \text { days/ } \\
\text { each } 28 \text {-day cycle. } \bullet \text { Cohort IV: CPI-444 } \\
\text { MTD + atezolizumab IV }\end{array}$ \\
\hline $\begin{array}{l}\text { NCT02817633 } \\
\text { Phase I } \\
\text { (recruiting, 2016) }\end{array}$ & $\begin{array}{l}- \text { Antagonist PD-L1 } \\
\text { mAb } \bullet \text { TSR-022 } \\
\text { (antagonist Tim-3 } \\
\text { mAb) }\end{array}$ & $\begin{array}{l}\text { Metastatic } \\
\text { tumors } \\
\text { including } \\
\text { MM }\end{array}$ & Tesaro, Inc. & $\begin{array}{l}\text { A Phase } 1 \text { dose escalation and } \\
\text { cohort expansion study of TSR-022, } \\
\text { an Anti-TIM-3 monoclonal antibody, } \\
\text { in patients with advanced solid } \\
\text { tumors }\end{array}$ & $\begin{array}{l}\text { - Part 1: Dose Escalation. 1a: dose escalation } \\
\text { TSR-022 alone. 1b: dose escalation TSR-022 } \\
\text { plus anti-PD-1 antibody. 1c: Phase } 2 \text { TSR- } \\
022 \text { MTD plus anti-PD-1 antibody. • Part 2: } \\
\text { expansion cohorts of Part } 1\end{array}$ \\
\hline $\begin{array}{l}\text { NCT02608268 } \\
\text { Phase I/II } \\
\text { (recruiting, 2015) }\end{array}$ & $\begin{array}{l}\text { - PDR001 (antagonist } \\
\text { PD-1 mAb) • } \\
\text { MBG453 (antagonist } \\
\text { Tim-3 mAb) }\end{array}$ & $\begin{array}{l}\text { Metastatic } \\
\text { tumors } \\
\text { including } \\
\text { MM }\end{array}$ & $\begin{array}{l}\text { Novartis } \\
\text { Pharmaceuticals }\end{array}$ & $\begin{array}{l}\text { Phase I-Ib/II open-label multi-center } \\
\text { study of the safety and efficacy of } \\
\text { MBG453 as single agent and in } \\
\text { combination with PDR001 in adult } \\
\text { patients with advanced malignancies }\end{array}$ & $\begin{array}{l}\text { - Cohort 1: MBG453 dose escalation. } \cdot \text { Cohort } \\
\text { 2: MBG453 dose escalation in combination with } \\
\text { PDR001 }\end{array}$ \\
\hline $\begin{array}{l}\text { NCT02983006 } \\
\text { Phase I } \\
\text { (recruiting, 2016) }\end{array}$ & $\begin{array}{l}- \text { Nivolumab } \\
\text { (antagonist PD-L1 } \\
\text { mAb) • DS-8273a } \\
\text { (TRAIL-DR5 mAb) }\end{array}$ & MM & $\begin{array}{l}\text { New York University } \\
\text { School of Medicine }\end{array}$ & $\begin{array}{l}\text { A Phase } 1 \text { study of TRAIL-DR5 } \\
\text { antibody DS-8273a administered } \\
\text { in combination with nivolumab in } \\
\text { subjects with unresectable Stage III } \\
\text { or Stage IV melanoma }\end{array}$ & $\begin{array}{l}\text { DS-8273a: starting dose } 4 \text { mg/kg IVQ } 3 \text { weeks. } \\
\text { Dose Escalation: } 8 \text { mg/kg IV Q } 3 \text { weeks, } \\
16 \text { mg/kg IV Q } 3 \text { weeks, } 24 \text { mg/kg IV Q } \\
3 \text { weeks, } 2 \text { mg/kg IV Q } 3 \text { weeks, } 4 \text { mg/kg } \\
\text { IV Q } 3 \text { weeks. • nivolumab: } 5 \text { mg/kg IV Q } \\
3 \text { weeks }\end{array}$ \\
\hline $\begin{array}{l}\text { NCT02471846 } \\
\text { Phase I } \\
\text { (recruiting, 2015) }\end{array}$ & $\begin{array}{l}- \text { Atezolizumab } \\
\text { (antagonist PD-1 } \\
\text { mAb) • GDC-0919 } \\
\text { (IDO inhibitor) }\end{array}$ & $\begin{array}{l}\text { Metastatic } \\
\text { tumors } \\
\text { including } \\
\text { MM }\end{array}$ & Genentech, Inc. & $\begin{array}{l}\text { A Phase Ib, open-label, dose- } \\
\text { escalation study of the safety } \\
\text { and pharmacology of GDC-0919 } \\
\text { administered with atezolizumab in } \\
\text { patients with locally advanced or } \\
\text { metastatic solid tumors }\end{array}$ & $\begin{array}{l}\text { - Relapsed cohorts to PD1/PD-L1 blockade } \\
\text { will receive GDC-0919 at MTD. • Untreated } \\
\text { advanced patients will receive escalation doses } \\
\text { of atezolizumab and GDC-0919 combinations. • } \\
\text { An expansion cohort of atezolizumab and GDC- } \\
0919 \text { combination at MTD }\end{array}$ \\
\hline $\begin{array}{l}\text { NCT02318277 } \\
\text { Phase I/II } \\
\text { (recruiting, 2014) }\end{array}$ & $\begin{array}{l}- \text { Durvalumab } \\
\text { (blocking PD-L1 } \\
\text { mAb) } \bullet \text { epacadostat } \\
\text { (IDO-1 inhibitor } \\
\text { molecule) }\end{array}$ & $\begin{array}{l}\text { Metastatic } \\
\text { tumors } \\
\text { including } \\
\mathrm{MM}\left(\mathrm{B}^{\mathrm{H}} \mathrm{H}^{+}\right)\end{array}$ & Incyte Corporation & $\begin{array}{l}\text { A Phase } 1 / 2 \text { study exploring the } \\
\text { safety, tolerability, and efficacy } \\
\text { of epacadostat (INCB024360) } \\
\text { in combination with durvalumab } \\
\text { (MEDI4736) in subjects with selected } \\
\text { advanced solid tumors (ECHO-203) }\end{array}$ & $\begin{array}{l}\text { Durvalumab IV at selected dose levels every } \\
2 \text { weeks plus epacadostat } 25 \mathrm{mg} \text { BID as } \\
\text { starting dose, followed by dose escalations until } \\
\text { MTD }\end{array}$ \\
\hline $\begin{array}{l}\text { NCT02327078 } \\
\text { Phase I/II } \\
\text { (recruiting, 2014) }\end{array}$ & $\begin{array}{l}\text { - Nivolumab (PD-1 } \\
\text { antagonist mab) • } \\
\text { epacadostat (IDO-1 } \\
\text { inhibitor) }\end{array}$ & $\begin{array}{l}\text { Metastatic } \\
\text { tumors } \\
\text { including } \\
\text { MM }\end{array}$ & Incyte Corporation & $\begin{array}{l}\text { A Phase } 1 / 2 \text { study of the safety, } \\
\text { tolerability, and efficacy of } \\
\text { epacadostat administered in } \\
\text { combination with nivolumab in select } \\
\text { advanced cancers (ECHO-204) }\end{array}$ & $\begin{array}{l}\text { - Phase 1: nivolumab IV } 3 \mathrm{mg} / \mathrm{kg} / 2 \text { weeks } \\
\text { plus epacadostat } 25 \mathrm{mg} \mathrm{BID} \text { as starting dose, } \\
\text { followed by dose escalations. • Phase } 2 \text { : } \\
\text { nivolumab } 240 \text { mg } 2 \text { weeks plus epacadostat } \\
\text { MTD }\end{array}$ \\
\hline
\end{tabular}


TABLE 2 | Continued

\begin{tabular}{|c|c|c|c|c|c|}
\hline $\begin{array}{l}\text { Trial identifier/ } \\
\text { study phase/ } \\
\text { status }\end{array}$ & $\begin{array}{l}\text { Combination } \\
\text { therapy }\end{array}$ & $\begin{array}{l}\text { Patient } \\
\text { condition }\end{array}$ & Sponsor & Official study title & Study design \\
\hline $\begin{array}{l}\text { NCT02073123 } \\
\text { Phase I/II } \\
\text { (recruiting, 2014) }\end{array}$ & $\begin{array}{l}\text { - Ipilimumab } \\
\text { (antagonist } \\
\text { CTLA-4 mAb) } \bullet \\
\text { pembrolizumab } \\
\text { (antagonist PD-1 } \\
\text { mAb) • nivolumab } \\
\text { (antagonist PD-1 } \\
\text { mAb) • indoximod } \\
\text { (IDO inhibitor) }\end{array}$ & MM & $\begin{array}{l}\text { NewLink Genetics } \\
\text { Corporation }\end{array}$ & $\begin{array}{l}\text { A Phase } 1 / 2 \text { study of the concomitant } \\
\text { administration of indoximod plus } \\
\text { immune checkpoint inhibitors (CPIs) } \\
\text { for adult patients with advanced or } \\
\text { MM }\end{array}$ & $\begin{array}{l}\text { - Indoximod 1,200 mg BID concurrently with } \\
\text { ipilimumab IV } 3 \mathrm{mg} / \mathrm{kg} / 3 \text { weeks/four doses. } \\
\text { Indoximod 1,200 mg BID and pembrolizumab IV } \\
\text { at } 2 \mathrm{mg} / \mathrm{kg} / 3 \text { weeks. • Indoximod 1,200 mg BID } \\
\text { and nivolumab IV at } 3 \mathrm{mg} / \mathrm{kg} / 4 \text { weeks }\end{array}$ \\
\hline $\begin{array}{l}\text { NCT02117362 } \\
\text { Phase I } \\
\text { (recruiting, 2014) }\end{array}$ & $\begin{array}{l}\bullet \text { Ipilimumab } \\
\text { (antagonist CTLA-4 } \\
\text { mAb) • GR-MD-02 } \\
\text { (Galectin-3 Inhibitor) }\end{array}$ & MM & $\begin{array}{l}\text { Providence Health } \\
\text { \& Services }\end{array}$ & $\begin{array}{l}\text { Phase IB study of a galectin inhibitor } \\
\text { (GR-MD-02) and ipilimumab in } \\
\text { patients with MM }\end{array}$ & $\begin{array}{l}\text { Cohorts with escalating doses of GR-MD-02 } \\
(1,2,4,8 \mathrm{mg} / \mathrm{kg}) 1 \text { hour before } 3 \mathrm{mg} / \mathrm{kg} \text { of } \\
\text { ipilimumab on days } 1,22,43 \text {, and } 65\end{array}$ \\
\hline $\begin{array}{l}\text { NCT02403778 } \\
\text { Phase II } \\
\text { (ongoing, not- } \\
\text { recruiting, 2015) }\end{array}$ & $\begin{array}{l}\text { - Ipilimumab (CTLA-4 } \\
\text { antagonist mab) } \bullet \\
\text { All-trans retinoic acid } \\
\text { (ATRA) }\end{array}$ & MM & $\begin{array}{l}\text { University of } \\
\text { Colorado, Denver }\end{array}$ & $\begin{array}{l}\text { Ipilimumab and ATRA combination } \\
\text { treatment of Stage IV melanoma }\end{array}$ & $\begin{array}{l}\text { - Arm A: ipilimumab } 10 \text { mg/kg/3 weeks/four } \\
\text { doses. • Arm B: ipilimumab } 10 \text { mg/kg/3 weeks/ } \\
\text { four doses plus } 150 \text { mg/m² ATRA orally for } \\
3 \text { days surrounding ipilimumab dosage }\end{array}$ \\
\hline $\begin{array}{l}\text { NCT02807844 } \\
\text { Phase I/II } \\
\text { (recruiting, 2016) }\end{array}$ & $\begin{array}{l}\text { - PDR001 (antagonist } \\
\text { PD-1 mAb) • } \\
\text { MCS110 (blocking } \\
\text { MCSF mAb) }\end{array}$ & $\begin{array}{l}\text { Metastatic } \\
\text { tumors } \\
\text { including } \\
\text { MM }\end{array}$ & $\begin{array}{l}\text { Novartis } \\
\text { Pharmaceuticals }\end{array}$ & $\begin{array}{l}\text { A Phase lb/ll, open label, multicenter } \\
\text { study of MCS110 in combination with } \\
\text { PDR001 in patients with advanced } \\
\text { malignancies }\end{array}$ & MCS110 combined with PDR001 \\
\hline $\begin{array}{l}\text { NCT02452424 } \\
\text { Phase I/II } \\
\text { (recruiting, 2015) }\end{array}$ & $\begin{array}{l}\text { - Pembrolizumab } \\
\text { (PD-1 mAb) • } \\
\text { PLX3397 (CSF1R } \\
\text { inhibitor) }\end{array}$ & $\begin{array}{l}\text { Metastatic } \\
\text { tumors } \\
\text { including } \\
\text { MM }\end{array}$ & Plexxikon & $\begin{array}{l}\text { Phase } 1 / 2 \text { a study of double-immune } \\
\text { suppression blockade by combining } \\
\text { a CSF1R inhibitor (PLX3397) with an } \\
\text { Anti-PD-1 antibody (pembrolizumab) } \\
\text { to treat advanced melanoma and } \\
\text { other solid tumors }\end{array}$ & $\begin{array}{l}\text { - Part 1: open-label, sequential PLX3397 dose } \\
\text { escalation with a fixed dose of pembrolizumab } \\
\text { (200 mg, IV) in approximately } 24 \text { patients with } \\
\text { advanced solid tumors. • Part 2: extension } \\
\text { cohort }\end{array}$ \\
\hline $\begin{array}{l}\text { NCT02880371 } \\
\text { Phase I/II } \\
\text { (recruiting, 2016) }\end{array}$ & $\begin{array}{l}- \text { Pembrolizumab } \\
\text { (antagonist PD-1 } \\
\text { mAb) • ARRY-382 } \\
(\text { CSF1R) }\end{array}$ & $\begin{array}{l}\text { Metastatic } \\
\text { tumors } \\
\text { including } \\
\text { MM }\end{array}$ & Array BioPharma & $\begin{array}{l}\text { A Study of ARRY-382 in combination } \\
\text { with pembrolizumab, a programmed } \\
\text { cell death receptor } 1 \text { (PD-1) antibody, } \\
\text { for the treatment of patients with } \\
\text { advanced solid tumors }\end{array}$ & $\begin{array}{l}- \text { Part A: escalating doses of ARRY-382 with } \\
\text { pembrolizumab } 2 \mathrm{mg} / \mathrm{kg} \text {. • Part B: ARRY-382 } \\
\text { at MTD with pembrolizumab } 2 \mathrm{mg} / \mathrm{kg} \text {. • Part C: } \\
\text { ARRY-382 at MTD with } 200 \mathrm{mg} \text { pembrolizumab }\end{array}$ \\
\hline
\end{tabular}

with GM-CSF $(75 \mu \mathrm{g})$ and UV1 peptide based-vaccine directed to hTERT is being tested in unresectable Stage III or Stage IV melanoma patients. UV1 vaccine $(300 \mu \mathrm{g})$ will be administered by injecting ID in the lower abdomen before and between treatments with ipilimumab, thereafter every 4 th week up to 28 weeks, and then at weeks 36 and 48. This study will analyze safety and tolerability of the combination and also will measure specific T-cell responses, quality of life, and treatment response by CT scans. A search for potential biomarkers of efficacy and safety studies will be also performed.

\section{Cytokines}

There are several trials combining ICKB with typical cytokines first assessed in CM patients as non-specific immunotherapy treatments, such as IL-2, IFN- $\alpha 2 b$, and GM-CSF (Table 1). Aldesleukin is a recombinant analog of the endogenous cytokine IL-2 that has immunoregulatory and antineoplastic activities. It promotes activation of T, $\mathrm{B}$, and NK cells; however, serious related adverse events were seen upon IL-2 administration (17). IL-2 was approved for treatment of metastatic renal cell carcinoma in 1992 and for metastatic melanoma (MM) in 1998 by FDA. Nowadays, IL-2 monotherapy is not the optimal and standard treatment for both metastatic renal cell carcinoma and MM but efforts to further improve the efficacy of IL-2 therapy are focused on combined therapies. Results from NCT00058279 combining ipilimumab with IL-2 revealed immune-related adverse events. A non-synergistic effect was observed, since the $22 \%$ objective response rate observed, results from the additive effect of the expected response rate for each therapy; however, long-term responses were still observed (12). NCT02983045 ongoing study will analyze ICKB in combination with NKTR-214, a prodrug for IL-2, conjugated to six releasable PEG chains. In a preclinical CM mouse model, this molecule showed 20 times preferential activation of $\mathrm{CD}^{+} \mathrm{T}$ cells (IL2R $\beta$ ) over Treg cells (IL2R $\alpha$ ) in comparison to aldesleukin. In this model, NKTR-214 proved efficacy as a single agent, and long-term immunity when combined with antagonist CTLA- $4 \mathrm{mAb}$, in addition to resistance to tumor rechallenge (18). NCT02748564 Phase Ib/II study will evaluate the safety and tolerability of IL-2 when given in combination with pembrolizumab to patients with advanced CM.

Adjuvant IFN- $\alpha 2 b$ increases disease-free survival (DFS) although not OS in CM patients but it is accompanied with considerable toxicity $(19,20)$; it is not universally considered as a gold standard treatment (21). Besides, the optimal dose and duration 
TABLE 3 | Other combinations in clinical trials with immunomodulatory monoclonal antibodies.

\begin{tabular}{|c|c|c|c|c|c|}
\hline $\begin{array}{l}\text { Trial identifier/ } \\
\text { study phase/ } \\
\text { status }\end{array}$ & Combination therapy & $\begin{array}{l}\text { Patient } \\
\text { condition }\end{array}$ & Sponsor & Official study title & Study design \\
\hline $\begin{array}{l}\text { NCT01740297 } \\
\text { Phase I/II } \\
\text { (completed, } \\
\text { 2015) }\end{array}$ & $\begin{array}{l}\text { - Ipilimumab (antagonist } \\
\text { CTLA-4 mAb) } \\
\text { talimogene laherparepvec } \\
\text { (oncolytic virus) }\end{array}$ & $\begin{array}{l}\text { Metastatic } \\
\text { melanoma } \\
(\mathrm{MM})\end{array}$ & Amgen & $\begin{array}{l}\text { Phase } 1 \mathrm{~b} / 2 \text {, multicenter, open-label trial } \\
\text { to evaluate the safety and efficacy of } \\
\text { talimogene laherparepvec and ipilimumab } \\
\text { compared to ipilimumab alone in subjects } \\
\text { with unresected, stage IIIB-IV melanoma }\end{array}$ & $\begin{array}{l}\text { - Experimental: Phase } 1 \mathrm{~b} \text { and Phase } 2 \text { Arm } 1 . \\
\text { Talimogene laherparepvec plus ipilimumab. • } \\
\text { Active Comparator: Phase } 2 \text { Arm } 2 . \\
\text { Ipilimumab }\end{array}$ \\
\hline $\begin{array}{l}\text { NCT02263508 } \\
\text { Phase lb/ } \\
\text { III (recruiting, } \\
\text { 2014) }\end{array}$ & $\begin{array}{l}\text { - Pembrolizumab } \\
\text { (antagonist PD-1 mAb) • } \\
\text { talimogene laherparepvec } \\
\text { (oncolytic virus) }\end{array}$ & MM & Amgen & $\begin{array}{l}\text { A Phase } 1 \mathrm{~b} / 3 \text {, multicenter, trial of } \\
\text { talimogene laherparepvec in combination } \\
\text { with pembrolizumab (MK-3475) for } \\
\text { treatment of unresectable stage IIIB to } \\
\text { IVM1c melanoma (MASTERKEY-265/ } \\
\text { KEYNOTE-034) }\end{array}$ & $\begin{array}{l}\text { - Experimental: Phase } 3 \text { Arm 1, talimogene } \\
\text { laherparepvec and pembrolizumab (MK-3475). } \\
\text { - Experimental: Phase } 3 \text { Arm 2: placebo and } \\
\text { pembrolizumab (MK-3475) }\end{array}$ \\
\hline $\begin{array}{l}\text { NCT02272855 } \\
\text { phase II } \\
\text { (ongoing, not- } \\
\text { recruiting, 2014) }\end{array}$ & $\begin{array}{l}\text { - Ipilimumab (agonist } \\
\text { CTLA-4 mAb) • HF10 } \\
\text { (vaccinia virus) }\end{array}$ & MM & $\begin{array}{l}\text { Takara Bio } \\
\text { Inc }\end{array}$ & $\begin{array}{l}\text { A Phase II study of combination treatment } \\
\text { with HF10, a Replication-competent HSV-1 } \\
\text { oncolytic virus, and ipilimumab in patients } \\
\text { with Stage IIIB, Stage IIIC, or Stage IV } \\
\text { unresectable or metastatic malignant } \\
\text { melanoma }\end{array}$ & $\begin{array}{l}\text { Patients will receive } 1.10^{7} \mathrm{TCID} 50 / \mathrm{mL} \text { HF10 } \\
\text { (four injections/once a week; two injections/ } \\
\text { once at } 3 \text { weeks) and ipilimumab } 3 \mathrm{mg} / \mathrm{kg} \\
\text { IV/3 weeks/four total doses }\end{array}$ \\
\hline
\end{tabular}

\begin{tabular}{|c|c|c|c|c|}
\hline $\begin{array}{l}\text { NCT03003676 } \\
\text { Phase I } \\
\text { (recruiting, } \\
\text { 2016) }\end{array}$ & $\begin{array}{l}\text { - Pembrolizumab } \\
\text { (antagonist PD-1 mAb) • } \\
\text { ONCOS-102 (oncolytic } \\
\text { virus) }\end{array}$ & $\mathrm{MM}$ & Targovax Oy & $\begin{array}{l}\text { A pilot study of sequential ONCOS-102, } \\
\text { an engineered oncolytic adenovirus } \\
\text { expressing GMCSF, and pembrolizumab } \\
\text { in patients with advanced or unresectable } \\
\text { melanoma progressing after PD1 blockade }\end{array}$ \\
\hline
\end{tabular}

Patients will receive three doses of intratumoral (i.t.) injection of ONCOS-102 (days 1, 4, and 8 ) at $3 \times 1011$ viral particles (VP), preceded by intravenous (i.v.) cyclophosphamide priming 1-3 days prior to day 1 . They will then receive pembrolizumab i.v., 2 mg/kg, on day 22 (week 3) and every 3 weeks thereafter until the end of treatment visit on day 169 (week 24)

\begin{tabular}{lllll}
\hline NCT01986426 & - Ipilimumab (antagonist & Metastatic & Lytix & A Phase I, open-label, multiarm, \\
Phase I & CTLA-4 mAb) & tumors & Biopharma & multicenter, multi-dose, dose escalation \\
(recruiting, & pembrolizumab & including & AS & study of LTX-315 as monotherapy or \\
2013) & $\begin{array}{l}\text { (antagonist PD-1 mAb) } \\
\text { LTX-315 (lytic peptide) }\end{array}$ & MM & & in combination with either ipilimumab \\
& & & or pembrolizumab in patients with \\
& & & transdermally accessible tumors
\end{tabular}

\begin{tabular}{llll}
\hline NCT02302339 & $\bullet$ Glembatumumab & MM & Celldex \\
Phase II & vedotin (gpNMB & Therapeutics \\
(recruiting, & conjugate-drug mAb) & & \\
2016) & varlilumab (CD27 agonist & \\
& mab) • nivolumab/ & \\
& pembrolizumab & \\
& $($ antagonist PD-1 mAb) &
\end{tabular}

- Arm A: LTX-315 monotherapy at single/ sequential lesions. • Arm B: LTX-315 monotherapy at concurrent multiple lesions. • Arm C: LTX-315 plus ipilimumab in MM patients. • Arm D: LTX-315 plus pembrolizumab in triple-negative breast cancer patients

A Phase 2 study of glembatumumab vedotin, an anti-gpNMB antibodydrug conjugate, as monotherapy or in combination with immunotherapies in patients with advanced melanoma

- Cohort A: glembatumumab vedotin IV on day 1/21 day cycle. $\cdot$ Cohort B: glembatumumab vedotin IV on day $1 / 21$ day cycle. Varlilumab IV on day 1 of cycles 1, 2, 4, 6, 8 and 10. • Cohort C: glembatumumab vedotin IV on day 1/21 day cycle. Nivolumab/pembrolizumab administered according to institutional standard of care

\begin{tabular}{|c|c|c|c|c|}
\hline $\begin{array}{l}\text { NCT02076633 } \\
\text { Phase II } \\
\text { (completed, } \\
\text { 2015) }\end{array}$ & $\begin{array}{l}\bullet \text { L19IL2 (HDAC4 mab } \\
\text { conjugated with IL-2) • } \\
\text { L19TNF (HDAC4 mab } \\
\text { conjugated with TNF) }\end{array}$ & MM & $\begin{array}{l}\text { Philogen } \\
\text { S.p.A. }\end{array}$ & $\begin{array}{l}\text { A Phase II study of intratumoral application } \\
\text { of L19IL2/L19TNF in melanoma patients } \\
\text { in clinical Stage III or Stage IV M1a with } \\
\text { presence of injectable cutaneous and/or } \\
\text { SC lesions }\end{array}$ \\
\hline $\begin{array}{l}\text { NCT02315066 } \\
\text { Phase I } \\
\text { (recruiting, } \\
\text { 2015) }\end{array}$ & $\begin{array}{l}- \text { PF-04518600 } \\
\text { (agonist OX40 mAb) • } \\
\text { PF-05082566 (agonist } \\
\text { 41BB mAb) }\end{array}$ & $\begin{array}{l}\text { Metastatic } \\
\text { tumors } \\
\text { including } \\
\text { MM }\end{array}$ & Pfizer & $\begin{array}{l}\text { A Phase 1, open-label, dose escalation } \\
\text { study of Pf-04518600 as a single agent } \\
\text { and in combination with Pf-05082566 in } \\
\text { patients with selected locally advanced or } \\
\text { metastatic carcinomas }\end{array}$ \\
\hline
\end{tabular}

Patients will be treated with intratumoral injections of 10 Mio IU L19IL2 and $312 \mu \mathrm{g}$ L19TNF once weekly for up to 4 weeks

\begin{tabular}{|c|c|c|c|c|c|}
\hline $\begin{array}{l}\text { NCT02714374 } \\
\text { Phase I } \\
\text { (recruiting, } \\
\text { 2016) }\end{array}$ & $\begin{array}{l}\text { - Eculizumab (C5 } \\
\text { neutralizing mab) • } \\
\text { GL-ONC1 (vaccinia virus) }\end{array}$ & $\begin{array}{l}\text { Metastatic } \\
\text { tumors } \\
\text { including } \\
\text { MM }\end{array}$ & $\begin{array}{l}\text { Kaitlyn Kelly, } \\
\text { MD }\end{array}$ & $\begin{array}{l}\text { An open label, non-randomized Phase } 1 \mathrm{~b} \\
\text { study to investigate the safety and effect of } \\
\text { the oncolytic virus GL-ONC1 administered } \\
\text { intravenously with or without eculizumab } \\
\text { prior to surgery to patients with solid organ } \\
\text { cancers undergoing surgery for curative- } \\
\text { intent or palliative resection }\end{array}$ & $\begin{array}{l}- \text { Arm A: GL-ONC1 escalation dose. - Arm B: } \\
\text { GL-ONC1 escalation dose plus eculizumab, } \\
\text { single dose on week 1/day } 1 \text { at } 900 \text { mg } \\
\text { 60-90 min prior to GL-ONC1 }\end{array}$ \\
\hline
\end{tabular}

- Part A1 -PF-04518600 will be administered IV every 14 days starting at a dose of $0.01 \mathrm{mg} /$ $\mathrm{kg}$, increasing until maximum tolerated dose (MTD) is determined. • Part B1 -PF-04518600 will be administered IV every 2 weeks starting at a dose of $0.1 \mathrm{mg} / \mathrm{kg}$ and PF-05082566 will be administered IV 4 weeks starting at a dose of $20 \mathrm{mg}$. Increases in dose will continue until MTD is determined

- Arm A: GL-ONC1 escalation dose. - Arm B: GL-ONC1 escalation dose plus eculizumab, single dose on week 1/day 1 at $900 \mathrm{mg}$ intravenously with or without eculizumab $\quad$ 60-90 min prior to GL-ONC1 cancers undergoing surgery for curativeintent or palliative resection 
of IFN- $\alpha 2 b$ treatment are still unclear $(22,23)$. IFN- $\alpha 2 b$ would have several mechanisms of action, from induction of apoptosis in tumor cells to activation of monocytes and macrophages favoring Ag processing. There are several ongoing trials combining ICKB with IFN- $\alpha 2 b$ or PEG-IFN- $\alpha 2 b$ (NCT01608594, NCT01708941, NCT02112032, NCT02339324, and NCT02174172). Low doses of cytokine GM-CSF proved to be a strong monocyte attractant and necessary to differentiate monocytes into DCs promoting a $\mathrm{T}_{\mathrm{H}} 1$ response (24); a combination of ipilimumab with this cytokine is also on the way (NCT02009397).

\section{Adoptive Cell Therapy}

One approach to restore the functionality of effector immune cells is to cultivate autologous tumor infiltrating lymphocyte (TIL) ex vivo after tumor resection and infused them back into the patient (25); this is defined as ACT. Combination of ACT with ICKB may counteract any inhibitory immune checkpoint signal from the tumor microenvironment, provided that $\mathrm{T}$ cell effectors have been expanded and activated in vitro in the presence of tumor Ags previous to treatment (Table 1). NCT02652455 will compare the effect of nivolumab administration prior to tumor resection and in vitro culture of TILs. These will be cultivated ex vivo with agonist CD137 mAb to augment $\mathrm{T}$ cell proliferation and infused them after chemotherapy-induced lymphodepletion of patients. They will be treated in vivo with IL-2 to support T cell proliferation. NCT01701674 will study the effect of ipilimumab before leukapheresis, while NCT02027935 will do it afterward.

\section{Stimulatory Immune Checkpoints}

CD40 is a costimulatory receptor that is essential for activating both innate and adaptive immune systems (26). CD40 binds its ligand CD40L, which is transiently expressed on T cells and other non-immune cells under inflammatory conditions. A wide spectrum of molecular and cellular processes is regulated by CD40 engagement including the initiation and progression of cellular and humoral adaptive immunity. Use of agonist CD40 mAbs with high-affinity fosters activation of APCs (DCs, monocytes, and B cells), leading to stimulation of tumor-specific immune responses. Recently, it was reported in a mouse tumor model that use of agonist CD $40 \mathrm{mAb}$ reversed resistance to PD-1, downregulating PD-1 levels in T cells via IL-12 production (27). Agonist CD40 mAb APX005M is currently being evaluated in Phase I/II trials in combination with ipilimumab (NCT03123783) or pembrolizumab (NCT02706353) (Table 1). NCT02554812 trial combines avelumab in different cohorts with agonist mAbs toward T cells costimulatory molecules $4-1 \mathrm{BB}$ and OX-40 (28) or neutralizing $\mathrm{mAb}$ toward $\mathrm{M}-\mathrm{CSF} / \mathrm{CSF} 1$ (macrophage colonystimulating factor) (29).

\section{Toll-Like Receptors (TLRs)/PAMP}

Toll-like receptors can detect a broad range of human pathogens, as well as a variety of molecules such as PAMP (pathogenassociated molecular patterns) that indicate tissue damage. This recognition triggers a cascade of innate and adaptive immune responses that fully activate the immune system. Agonist TLR
mAbs support this response. It was reported that triggering of TLR3 induces T-cell activation and a strong upregulation of HLA-I and PD-L1 in neuroblastoma and melanoma cells $(30,31)$. Therefore, ICKB will counteract limitation of the T cell response induced by TLR signaling. Ongoing trials include combinations of PD-1 and CTLA-4 ICKB with agonist TLR3 and TLR9 mAbs (NCT02643303, NCT02644967, and NCT02668770). Trial NCT02981303 will assess Imprime PGG, a $\beta-1,3 / 1,6$ glucan PAMP molecule isolated from the cell wall of a proprietary Saccharomyces, in combination with pembrolizumab (Table 1).

\section{ICKB Combined with Targeting of Immunosuppressive Molecules/Pathways Other ICKB}

Immune checkpoint blockade is also being assessed in combinations with the targeting of other molecules/pathways that promote an immunosuppressive environment (Table 2). For instance, there are trials targeting several ICKB. NCT02743819 trial combines pembrolizumab with ipilimumab in advanced patients which, following treatment with $\mathrm{PD}-1 / \mathrm{PD}-\mathrm{L} 1 \mathrm{mAb}$, either progress or present stable disease/initial response for more than 24 weeks. NCT02381314 studies in B7-H3 expressing tumors such as CM, the combination of ipilimumab with enoblituzumab, a B7-H3 $\mathrm{mAb}$ was designed to improve ADCC by increasing FcR affinity. NCT02460224 analyzes the combination of LAG525 and PDR001, antagonist mAbs for LAG-3 and PD-1, respectively. LAG-3 is an immune checkpoint that binds a non-holomorphic region of the MHC-II molecule and has an important role in the tumor microenvironment. It was reported that soluble-LAG-3 binds to immature DCs, promoting their maturation (32). However, LAG-3 is involved in alternative activation of plasmacytoid DCs in melanoma lesions (33). Interaction of MHC-II on APCs with LAG3 downregulates T-cell proliferation and activation (34). In agreement, LAG-3 mediates resistance to apoptosis on MHC-II expressing melanoma cells (35). LAG-3 is substantially expressed on melanoma TILs, including those with potent immunosuppressive activity. LAG3 was shown to have a synergistic action with the PD-1/PD-L1 axis, critical for releasing an antitumor immune response. In a mouse melanoma model, tumor-specific $\mathrm{CD}^{+}$effector T-cells showed traits of chronic exhaustion, with high expression levels of PD-1, TIM-3, 2B4, TIGIT, and LAG-3 inhibitory molecules. Blockade with a combination of anti-PDL1 and anti-LAG-3 mAbs overcame the requirement to deplete tumor-specific Tregs in this model (36). The PD-1 expression on $\mathrm{CD}^{+}$TILs identified a repertoire of clonally expanded tumorreactive cells, including mutated neoAg-specific $\mathrm{CD}^{+} \mathrm{T}$-cells; these cells expressed LAG-3 and Tim-3 (37). It has recently been described that ipilimumab expanded $\mathrm{T}$ cells in patients with higher expression levels of CD27, intracellular CTLA-4, TIM-3, and LAG-3, which can be taken into account for future combination trials (38).

Adenosine-A2A receptor (A2Ar), an ectonucleotidase that catabolizes the hydrolysis of extracellular adenosine monophosphate (AMP) to adenosine, is a novel metabolic target for ICKB. In preclinical models, it was shown that expression of A2Ar on myeloid cells suppressed $\mathrm{T}$ and NK cell responses in 
the solid tumor microenvironment (39). Also, A2Ar blockade enhanced antitumor activity of PD-1 and CTLA-4 ICKB (40). NCT02655822 is on the way combining PD-1 ICKB with an A2Ar inhibitor molecule.

\section{T-Cell Exhaustion}

TIM-3 was first identified as a specific $\mathrm{T}_{\mathrm{H}} 1$ receptor. When it binds to galectin-9, it generates an inhibitory signal that results in apoptosis of $\mathrm{T}_{\mathrm{H}} 1$ cells (41). TIM-3 was also described as a marker of T-cell exhaustion (38). TIM-3 is also expressed by NK cells and naive DCs, acting in synergy with TLR signaling to induce inflammation. Expression of TIM-3 in monocytes and macrophages promotes phagocytosis of apoptotic cells through interaction with phosphatidylserine, which enhances Ag cross-presentation (42). Also, TIM-3 binds HMGB1, impairing its recruitment of nucleic acids into endosomes, a key step in the sensing of DNA by the innate immune system, promoting tumor escape (43). Notably, it was shown that PD-1 and Tim-3 limited the expansion of tumor Ag-specific CD8 ${ }^{+} \mathrm{T}$ cells induced by a melanoma peptide vaccine, as dual blockade enhanced the expansion and cytokine production of vaccine-induced $\mathrm{CD}^{+} \mathrm{T}$ cells in vitro (44). NCT02817633 and NCT02608268 are ongoing combining ICKB with an antagonist Tim-3 mAb (Table 2).

\section{Tumor Immune Microenvironment}

NCT02983006 trial is testing the combination of nivolumab with DS-8273a (Table 2). This agonist mAb showed selective targeting of MDSC through TNF-receptor TRAIL-DR2, without affecting other mature myeloid or lymphoid cells (45). As an agonist of TRAIL-DR5 to induce apoptosis in tumor cells, in a Phase I trial DS-8273 as monotherapy was well tolerated but no objective responses were observed, although decreases in MDSC temporally associated with DS-8273a exposure were observed (46).

Indoleamine 2,3-dioxygenase is the first and rate-limiting enzyme involved in tryptophan catabolism, which can halt T-cells growth. In cancer, IDO is expressed within the tumor itself as well as in the tumor microenvironment, where it promotes the establishment of peripheral immune tolerance to tumor Ags. On the tumor side, lymph node CM cells express IDO, recruiting Treg, which is associated with a poor outcome (47). At the tumor microenvironment, IDO promotes MDSC recruitment by a mechanism dependent on Tregs (48); it also inhibits NK cell function along with PGE-2 (49). Activated T cells in vitro induce MDSC function through IL-10; these MDSC secrete ARG-1 and IDO and express PD-L1 and MHC-II, leading to upregulation of PD-1 and LAG-3 on T-cells, promoting an immunosuppressive tumor microenvironment (50). In CM patients, high levels of circulating $\mathrm{PD}-\mathrm{Ll}^{+}$cytotoxic T-cells were associated with increased expression levels of CTLA-4 in Tregs and IDO in MDSC and plasmacytoid DCs. All these parameters were related to a negative outcome, independent of disease stage (51).

It is interesting to note that IDO is an immunogenic protein, therefore, activation of pro-inflammatory IDO-specific $\mathrm{CD}^{+}$ responses may delay or overcome the immunosuppressive actions of IDO, consequence of early expression in maturing APCs; however, IDO-specific Tregs may enhance IDO-mediated immune suppression (47). In mouse melanoma models, IDO is an essential mechanism of resistance to ICKB, including CTLA-4 and PD-1. CTLA-4 blockade combined with IDO inhibitors strongly synergizes to mediate tumor rejection (49). It is postulated that following melanoma infiltration by lymphocytes, upregulation of PD-L1, IDO, and Tregs is regulated by an intrinsic immune mechanism (52). And that combination of CTLA-4, PD-1/PD-L1, and IDO blockade restores IL-2 production and proliferation of $\mathrm{CD}^{+} \mathrm{T}$-cells (53). It was recently reported that melanoma expresses high levels of IDO and galectin-3, which upregulate Tregs, suppressing the expansion of tumor-specific T cells cultivated for ACT, which could be reversed by blockade of IDO and galectin-3 (54). Trials combining ICKB with inhibitors of IDO (NCT02471846, NCT02318277, NCT02327078, and NCT02073123) or galectin-3 (NCT02117362) are currently on the way (Table 2).

NCT02403778 trial proposes the combination of ipilimumab with all-trans retinoic acid (ATRA), a derivative of vitamin A (Table 2). ATRA induces maturation of immunosuppressive MDSCs into myeloid cells $(55,56)$; this was shown to be of benefit in a lung cancer vaccine and ACT for sarcomas $(57,58)$. Thus, this combination is designed to decrease MDSCs and differentiate immature monocytes into mature DCs and increase tumor Ag-specific T-cell responses. In this trial, ATRA single-arm versus ATRA with ipilimumab combined-arm will be compared.

Finally, other combinations of ICKB and targeting the tumor microenvironment include antagonist $\mathrm{mAbs}$ for M-CSF/CSF1 (NCT02807844) or its receptor MCSFR/CSF1R (NCT02452424 and NCT02880371) (Table 2). Interaction of $\alpha 4 \beta 1$ integrin from extracellular matrix with MCSF receptor leads to the activation of Rac2 and regulation of macrophage toward a M2 immunosuppressive phenotype (59). In a melanoma mouse model, targeting of CSF1R on MDSCs overcomes resistance to IDO-expressing melanoma cells (60).

\section{Other Combinations with Immunomodulatory mAbs}

There are several oncolytic viruses that have shown to promote an immunogenic cell death leading to a $\mathrm{T}_{\mathrm{H}} 1$ response; combination with ICKB is aimed to sustain in time this tumor microenvironment (61). Talimogene laherparepvec (T-VEC, Imlygic) is a genetically modified, attenuated, herpes simplex virus type 1 designed to promote an antitumor response through selective viral replication in tumor cells and stimulation of systemic antitumor immunity through GM-CSF (62). This was the first oncolytic viral therapy to be approved by the FDA in 2015 for intralesional treatment of unresectable lesions in patients with melanoma recurrent after the initial surgery. The combination of T-VEC with ipilimumab in a Phase I trial proved to be safe and appeared to have greater efficacy than single agents (NCT01740297) (63). NCT02263508 is a Phase $1 \mathrm{~b} / 3$ study that will assess the combination of talimogene laherparepvec with pembrolizumab in unresectable CM patients. Combination studies with other oncolytic virus include NCT02272855 trial, which will analyze CTLA-4 ICKB with HF10, an oncolytic virus that has shown to induce angiogenesis and affluence of $\mathrm{CD}^{+} \mathrm{T}$-cells at 
the tumor microenvironment (64). Finally, in the NCT03003676 study the combination of pembrolizumab with ONCOS-102, an engineered oncolytic Adenovirus expressing GM-CSF, will be analyzed in $\mathrm{CM}$ patients that have progressed to the PD-1 blockade.

The NCT01986426 study is designed to assess the safety, tolerability, and efficacy of different intratumoral dosing regimens of LTX-315; a lytic-peptide that induces immunogenic cell death; it will be assessed as monotherapy or in combination with ipilimumab or pembrolizumab. It was shown in mouse models that this peptide overcomes tumor resistance to CTLA-4 ICKB (65) (Table 1).

The NCT02302339 study will examine the effectiveness and safety of glembatumumab vedotin as monotherapy and in combination with either nivolumab or pembrolizumab (Table 3). Glembatumumab vedotin $\mathrm{mAb}$ is conjugated to the cytotoxic drug monomethyl auristatin E. This mAb targets glycoprotein NMB, expressed on the surface of tumor cells, releasing the drug and inducing tumor cell death. Combinations with immunotherapy include pembrolizumab/nivolumab and varlilumab, an agonist $\mathrm{mAb}$ of the T-cell costimulatory receptor CD27. NCT02076633 trial also examines conjugated $\mathrm{mAbs}$ for treatment of metastatic CM patients; L19IL2 targets melanoma cells through HDAC4 and it is conjugated to IL-2; instead L19TNF is conjugated to TNF $\alpha$, exerting its major effects via a preferential toxicity for the endothelial cells of the tumor-associated vasculature, therefore, increasing an antitumor immune response. Preclinical data suggest that intratumoral administration of these conjugates can be more effective.

Another approach explores the synergy of two agonist mAbs targeting the T-cells costimulatory molecules OX40 and 41BB $(25,66)$ (NCT02315066) (Table 3). Finally, NCT02714374 ongoing trial is combining GL-ONC1, a genetically modified oncolytic vaccinia virus, with eculizumab, a neutralizing $\mathrm{C} 5 \mathrm{mAb}$, with the goal that GL-ONC1 remains in the body long before being cleared by the immune system.

\section{DISCUSSION}

Combined immunotherapy involving mAbs and other immunomodulatory strategies is an emerging field. There is no still any such combination therapy approved. The immune system should be considered as one interrelated signaling network where targeting different points may act synergistically to promote anticancer effects. Proper immune stimulation and blockade of immunosuppression can be seen as a "push and release" strategy, where both are critical for the efficacy of an anti-cancer immunotherapy (Figure 1). ICKB is currently being assessed in combination with immune stimulatory strategies, such as vaccination, cytokines, ACT, stimulatory immune checkpoint agonists, and targeting of TLRs. Other approaches combine ICKB with targeting of several immune suppressive mechanisms, such as blocking other immune checkpoints, T-cell exhaustion inhibition, and promotion of an antitumor microenvironment.

The idea of combining ICKB with immunomodulatory strategies such as vaccines is very attractive, given that in some cases amplification of Ag-specific T cells, as well as the induction of antibodies recognizing tumor Ags are observed after vaccination. Blocking of immune checkpoints may result in effector $\mathrm{T}$ cells that could attain potent tumor destruction more potently; a useful $\mathrm{T}$ helper function and modulation of Tregs will result in the expansion of cytotoxic T cell effectors. However, vaccines, in general, have shown a low $10-15 \%$ rate of clinical responses, with still a lack of efficacy to eradicate tumor masses and avoid further dissemination in metastatic patients (67). Most of the clinical trials revised in this work are being assessed in advanced CM patients, thus immune suppression, both systemic and local, can be hard to overcome even with ICKB, since there are patients that do not respond at all. Vaccination strategies may be more useful when administered in the adjuvant setting to control tumor relapse in high-risk stage II-III CM patients (68), and thus, their combination with ICKB may hold the promise of durable clinical benefit avoiding metastases to distant organs and achieving prolonged OS.

Assessment of clinical responses in ICKB cancer treatments can be challenging since traditional Response Evaluation Criteria In Solid Tumors, RECIST, may underestimate the actual response that can be delayed and atypical, as evidenced in patients treated with ICKB (69). The immune-related response criteria have been established to allow patients to continue treatment after the first progression until a new progression is presented, given the chance of eventual clinical benefit to more patients (70). It should be taken into account that there are both constitutive and acquired IKCB resistance mechanisms compromising treatment outcome (71-73).

Identification of early predictors of response is desirable to identify patients that would benefit the most and avoid unnecessarily prolonged treatments. Regarding ICKB biomarkers at the local level, an association of PD-L1 expression in pretreatment tumor biopsies with objective response to anti-PD-1/ PD-L1 therapy has been observed given the constant finding that PD-L1 expression is enriched in anti-PD-1/PD-L1 therapy responders in several tumors (74). Weighted-average ORR across several studies for patients whose tumors were tested for $\mathrm{PD}-\mathrm{L} 1$ is $29 \%$; if the tumor expresses PD-L1, these increases to $48 \%$. However, a significant proportion of responding patients with PD-L1 negative-tumors were observed. Also, high-density infiltration of CD8 T-cells in tumor biopsies has been associated with PD-L1 expression in tumor cells; it was associated independently with an improved prognosis, with increased time to development of brain metastases in CM patients (75). Also, it was recently reported that PD-L2 expression in metastatic CM was associated with immune infiltration and a better prognosis independently of therapy of choice (76). Other proposed biomarkers for selecting which patients are likely to benefit from cancer immunotherapies are the tumor mutational load and microsatellite in the stability. CM is a tumor with a high rate of mutation (1), and thus with a higher probability of neoAg generation, increasing the number of immunogenic structures that could stimulate a more potent and broad repertoire of antitumor immune effectors. In the same way, microsatellite instability is a frequent event in CM which accounts for tumor immunogenicity, contributing to making of CM a pathology suitable for immunotherapy (77). 
At the peripheral level, serum IL-8 concentrations actually reflect tumor burden (78). It was recently reported that measurement of serum IL-8 levels 2-3 weeks following starting therapy can predict response and OS in metastatic CM patients treated with PD-1 ICKB, even before imaging evaluation (79). Also, there are recent publications by two independent groups which reported that assessment of circulating cell-free DNA from tumors in CM patients receiving ICKB treatment is an accurate predictor of tumor response, PFS and OS, as patients with elevated ctDNA on therapy had a poor prognosis $(80,81)$.

In the combination of several immunotherapy strategies, identifying which patients are likely to respond to therapy will be even more challenging. This is given the complexity of the immune system, and the limited understanding of its regulation and multiple interactions between immune cells, immune-modulating molecules, tumor cells, and other compartments of the tumor microenvironment, such as the lymphatic and blood systems.

\section{CONCLUSION}

Monoclonal antibodies have gained evidence of their effectiveness for cancer treatment. This seems to be the tip of an iceberg, as we are learning that not only targeting the tumor but also

\section{REFERENCES}

1. Alexandrov LB, Nik-Zainal S, Wedge DC, Aparicio SAJR, Behjati S, Biankin AV, et al. Signatures of mutational processes in human cancer. Nature (2013) 500:415-21. doi:10.1038/nature12477

2. Shain AH, Yeh I, Kovalyshyn I, Sriharan A, Talevich E, Gagnon A, et al. The genetic evolution of melanoma from precursor lesions. $N$ Engl J Med (2015) 373:1926-36. doi:10.1056/NEJMoa1502583

3. Madorsky Rowdo FP, Baron A, Urrutia M, Mordoh J. Immunotherapy in cancer: a combat between tumors and the immune system; You Win Some, You Lose Some. Front Immunol (2015) 6:127. doi:10.3389/fimmu.2015.00127

4. Schumacher TN, Schreiber RD. Neoantigens in cancer immunotherapy. Science (2015) 348:69-74. doi:10.1126/science.aaa4971

5. Galon J, Fox BA, Bifulco CB, Masucci G, Rau T, Botti G, et al. Immunoscore and immunoprofiling in cancer: an update from the melanoma and immunotherapy bridge 2015. J Transl Med (2016) 14:273. doi:10.1186/s12967-016-1029-z

6. Aris M, Barrio MM, Mordoh J. Lessons from cancer immunoediting in cutaneous melanoma. Clin Dev Immunol (2012) 2012:192719. doi:10.1155/ 2012/192719

7. Hodi FS, O’Day SJ, McDermott DF, Weber RW, Sosman JA, Haanen JB, et al. Improved survival with ipilimumab in patients with metastatic melanoma. $N$ Engl J Med (2010) 363:711-23. doi:10.1056/NEJMoa1003466

8. Leach DR, Krummel MF, Allison JP. Enhancement of antitumor immunity by CTLA-4 blockade. Science (1988) 7:1734-6.

9. Dong H, Strome SE, Salomao DR, Tamura H, Hirano F, Flies DB, et al. Tumor-associated B7-H1 promotes T-cell apoptosis: a potential mechanism of immune evasion. Nat Med (2002) 8:793-800. doi:10.1038/nm730

10. Robert C, Long GV, Brady B, Dutriaux C, Maio M, Mortier L, et al. Nivolumab in previously untreated melanoma without BRAF mutation. $N$ Engl J Med (2015) 372:320-30. doi:10.1056/NEJMoa1412082

11. Robert C, Ribas A, Wolchok JD, Hodi FS, Hamid O, Kefford R, et al. Anti-programmed-death-receptor-1 treatment with pembrolizumab in ipilimumab-refractory advanced melanoma: a randomised dose-comparison cohort of a phase 1 trial. Lancet (2014) 6736:1-9. doi:10.1016/S0140-6736(14) 60958-2

12. Schadendorf D, Hodi FS, Robert C, Weber JS, Margolin K, Hamid O, et al. Pooled analysis of long-term survival data from phase II and phase III trials of ipilimumab in unresectable or metastatic melanoma. J Clin Oncol (2015) 33:1889-94. doi:10.1200/JCO.2014.56.2736 modulating the immune response, may be a powerful way to achieve long-term clinical responses. In this way, mAbs can be again considered "magic bullets" targeting molecules with different immunomodulatory effects. We have revisited most of the current clinical trials that explore combined use of immunomodulatory mAbs with different immunotherapeutic approaches, with the aim to improve and/or potentiate clinical responses in CM patients. This is an exciting and expanding research field that is rapidly spreading to other tumor types.

\section{AUTHOR CONTRIBUTIONS}

MA and MB: conception and design of the review; manuscript writing. JM: conception and design of the review.

\section{FUNDING}

MA, JM, and MB are members of CONICET, Argentina. This work was supported by grants from CONICET, Agencia Nacional de Promoción Científica y Tecnológica (ANPCyT), Instituto Nacional del Cáncer-Ministerio de Salud de la Nación Argentina (INC-MSal), Fundación Sales, Fundación Cáncer, and Fundación Pedro F. Mosoteguy, Argentina.

13. Andersen MH. Anti-regulatory T cells. Semin Immunopathol (2017) 39 317-26. doi:10.1007/s00281-016-0593-x

14. Weber JS, Kudchadkar RR, Yu B, Gallenstein D, Horak CE, Inzunza HD, et al. Safety, efficacy, and biomarkers of nivolumab with vaccine in ipilimumab-refractory or -naive melanoma. J Clin Oncol (2013) 31:4311-8. doi:10.1200/ JCO.2013.51.4802

15. Wilgenhof S, Van Nuffel AMT, Corthals J, Heirman C, Tuyaerts S, Benteyn D, et al. Therapeutic vaccination with an autologous mRNA electroporated dendritic cell vaccine in patients with advanced melanoma. J Immunother (2011) 34:448-56. doi:10.1097/CJI.0b013e31821dcb31

16. Benteyn D, Van Nuffel AMT, Wilgenhof S, Corthals J, Heirman C, Neyns B, et al. Characterization of CD8+ T-cell responses in the peripheral blood and skin injection sites of melanoma patients treated with mRNA electroporated autologous dendritic cells (TriMixDC-MEL). Biomed Res Int (2013) 2013:976383. doi:10.1155/2013/976383

17. Shaker MA, Younes HM. Interleukin-2: evaluation of routes of administration and current delivery systems in cancer therapy. J Pharm Sci (2009) 98:2268-98. doi:10.1002/jps.21596

18. Charych DH, Hoch U, Langowski JL, Lee SR, Addepalli MK, Kirk PB, et al. NKTR-214, an engineered cytokine with biased IL2 receptor binding, increased tumor exposure, and marked efficacy in mouse tumor models. Clin Cancer Res (2016) 22. doi:10.1158/1078-0432.CCR15-1631 Available from: http://clincancerres.aacrjournals.org/content/22/ $3 / 680$,

19. Kirkwood JM, Bender C, Agarwala S, Tarhini A, Shipe-Spotloe J, Smelko B, et al. Mechanisms and management of toxicities associated with high-dose interferon alfa-2b therapy. JClin Oncol (2002) 20:3703-18. doi:10.1200/ JCO.2002.03.052

20. Eggermont AMM, Suciu S, Testori A, Santinami M, Kruit WHJ, Marsden J, et al. Long-term results of the randomized phase III trial EORTC 18991 of adjuvant therapy with pegylated interferon alfa-2b versus observation in resected stage III melanoma. J Clin Oncol (2012) 30:3810-8. doi:10.1200/ JCO.2011.41.3799

21. Mocellin S, Lens MB, Pasquali S, Pilati P, Chiarion Sileni V. Interferon alpha for the adjuvant treatment of cutaneous melanoma. Cochrane Database Syst Rev (2013) 6:CD008955. doi:10.1002/14651858.CD008955.pub2

22. Eggermont AMM, Suciu S, MacKie R, Ruka W, Testori A, Kruit W, et al. Post-surgery adjuvant therapy with intermediate doses of interferon alfa $2 b$ versus observation in patients with stage IIb/III melanoma (EORTC 
18952): randomised controlled trial. Lancet (2005) 366:1189-96. doi:10.1016/ S0140-6736(05)67482-X

23. Tarhini AA, Kirkwood JM, Gooding WE, Cai C, Agarwala SS. Durable complete responses with high-dose bolus interleukin-2 in patients with metastatic melanoma who have experienced progression after biochemotherapy. J Clin Oncol (2007) 25:3802-7. doi:10.1200/JCO.2006.10.2822

24. Parmiani G, Castelli C, Pilla L, Santinami M, Colombo MP, Rivoltini L. Opposite immune functions of GM-CSF administered as vaccine adjuvant in cancer patients. Ann Oncol (2007) 18:226-32. doi:10.1093/annonc/ mdl158

25. Kvistborg P, Shu CJ, Heemskerk B, Fankhauser M, Thrue CA, Toebes M, et al. TIL therapy broadens the tumor-reactive CD8(+) T cell compartment in melanoma patients. Oncoimmunology (2012) 1:409-18. doi:10.4161/ onci. 18851

26. Elgueta R, Benson MJ, de Vries VC, Wasiuk A, Guo Y, Noelle RJ. Molecular mechanism and function of CD40/CD40L engagement in the immune system. Immunol Rev (2009) 229:152-72. doi:10.1111/j.1600-065X.2009. 00782.x

27. Ngiow SF, Young A, Blake SJ, Hill GR, Yagita H, Teng MWL, et al. Agonistic $\mathrm{CD} 40 \mathrm{mAb}$-driven IL12 reverses resistance to anti-PD1 in a T-cell-rich tumor. Cancer Res (2016) 76:6266-77. doi:10.1158/0008-5472.CAN-16-2141

28. Kumari A, Garnett-Benson C. Effector function of CTLs is increased by irradiated colorectal tumor cells that modulate OX-40L and 4-1BBL and is reversed following dual blockade. BMC Res Notes (2016) 9:92. doi:10.1186/ s13104-016-1914-9

29. Masek-Hammerman K, Peeva E, Ahmad A, Menon S, Afsharvand M, Peng $\mathrm{Qu} \mathrm{R}$, et al. Monoclonal antibody against macrophage colonystimulating factor suppresses circulating monocytes and tissue macrophage function but does not alter cell infiltration/activation in cutaneous lesions or clinical outcomes in patients with cutaneous lupus ery. Clin Exp Immunol (2016) 183:258-70. doi:10.1111/cei.12705

30. Boes M, Meyer-Wentrup F. TLR3 triggering regulates PD-L1 (CD274) expression in human neuroblastoma cells. Cancer Lett (2015) 361:49-56. doi:10.1016/j.canlet.2015.02.027

31. Taube JM, Young GD, McMiller TL, Chen S, Salas JT, Pritchard TS, et al. Differential expression of immune-regulatory genes associated with PD-L1 display in melanoma: implications for PD-1 pathway blockade. Clin Cancer Res (2015) 21:3969-76. doi:10.1158/1078-0432.CCR-15-0244

32. Andreae S, Buisson S, Triebel F. MHC class II signal transduction in human dendritic cells induced by a natural ligand, the LAG-3 protein (CD223). Blood (2003) 102:2130-7. doi:10.1182/blood-2003-01-0273

33. Camisaschi C, De Filippo A, Beretta V, Vergani B, Villa A, Vergani E, et al. Alternative activation of human plasmacytoid DCs in vitro and in melanoma lesions: involvement of LAG-3. J Invest Dermatol (2014) 134:1893-902. doi:10.1038/jid.2014.29

34. Huard B, Prigent P, Pagès F, Bruniquel D, Triebel F. T cell major histocompatibility complex class II molecules down-regulate CD4+ T cell clone responses following LAG-3 binding. Eur J Immunol (1996) 26:1180-6. doi:10.1002/ eji. 1830260533

35. Hemon P, Jean-Louis F, Ramgolam K, Brignone C, Viguier M, Bachelez H, et al. MHC class II engagement by its ligand LAG-3 (CD223) contributes to melanoma resistance to apoptosis. JImmunol (2011) 186:5173-83. doi:10.4049/jimmunol.1002050

36. Goding SR, Wilson KA, Xie Y, Harris KM, Baxi A, Akpinarli A, et al. Restoring immune function of tumor-specific CD4+ $\mathrm{T}$ cells during recurrence of melanoma. J Immunol (2013) 190:4899-909. doi:10.4049/ jimmunol.1300271

37. Gros A, Robbins PF, Yao X, Li YF, Turcotte S, Tran E, et al. PD-1 identifies the patient-specific CD8+ tumor-reactive repertoire infiltrating human tumors. J Clin Invest (2014) 124:2246-59. doi:10.1172/JCI73639

38. Bjoern J, Lyngaa R, Andersen R, Rosenkrantz LH, Hadrup SR, Donia M, et al. Influence of ipilimumab on expanded tumour derived $\mathrm{T}$ cells from patients with metastatic melanoma. Oncotarget (2017) 8:27062-74. doi:10.18632/ oncotarget. 16003

39. Cekic C, Day Y-J, Sag D, Linden J. Myeloid expression of adenosine A2A receptor suppresses $\mathrm{T}$ and $\mathrm{NK}$ cell responses in the solid tumor microenvironment. Cancer Res (2014) 74:7250-9. doi:10.1158/0008-5472.CAN-13-3583

40. Mediavilla-Varela M, Castro J, Chiappori A, Noyes D, Hernandez DC, Stagg J, et al. A novel antagonist of the immune checkpoint protein adenosine
A2a receptor restores tumor-infiltrating lymphocyte activity in the context of the tumor microenvironment. Neoplasia (2017) 19:530-6. doi:10.1016/j. neo.2017.02.004

41. Zhu C, Anderson AC, Schubart A, Xiong H, Imitola J, Khoury SJ, et al. The Tim-3 ligand galectin-9 negatively regulates T helper type 1 immunity. Nat Immunol (2005) 6:1245-52. doi:10.1038/ni1271

42. Nakayama M, Akiba H, Takeda K, Kojima Y, Hashiguchi M, Azuma M, et al. Tim-3 mediates phagocytosis of apoptotic cells and cross-presentation. Blood (2009) 113:3821-30. doi:10.1182/blood-2008-10-185884

43. Chiba S, Baghdadi M, Akiba H, Yoshiyama H, Kinoshita I, Dosaka-Akita H, et al. Tumor-infiltrating DCs suppress nucleic acid-mediated innate immune responses through interactions between the receptor TIM-3 and the alarmin HMGB1. Nat Immunol (2012) 13:832-42. doi:10.1038/ni.2376

44. Fourcade J, Sun Z, Pagliano O, Chauvin J-M, Sander C, Janjic B, et al. PD-1 and Tim- 3 regulate the expansion of tumor antigen-specific $\mathrm{CD} 8+\mathrm{T}$ cells induced by melanoma vaccines. Cancer Res (2014) 74:1045-55. doi:10.1158/00085472.CAN-13-2908

45. Dominguez GA, Condamine T, Mony S, Hashimoto A, Wang F, Liu Q, et al. Selective targeting of myeloid-derived suppressor cells in cancer patients using DS-8273a, an agonistic TRAIL-R2 antibody. Clin Cancer Res (2016) 23(12):2942-50. doi:10.1158/1078-0432.CCR-16-1784

46. Forero A, Bendell JC, Kumar P, Janisch L, Rosen M, Wang Q, et al. Firstin-human study of the antibody DR5 agonist DS-8273a in patients with advanced solid tumors. Invest New Drugs (2017) 35:298-306. doi:10.1007/ s10637-016-0420-1

47. Brody JR, Costantino CL, Berger AC, Sato T, Lisanti MP, Yeo CJ, et al. Expression of indoleamine 2,3-dioxygenase in metastatic malignant melanoma recruits regulatory $\mathrm{T}$ cells to avoid immune detection and affects survival. Cell Cycle (2009) 8:1930-4. doi:10.4161/cc.8.12.8745

48. Holmgaard RB, Zamarin D, Li Y, Gasmi B, Munn DH, Allison JP, et al. Tumorexpressed IDO recruits and activates MDSCs in a treg-dependent manner. Cell Rep (2015) 13:412-24. doi:10.1016/j.celrep.2015.08.077

49. Pietra G, Manzini C, Rivara S, Vitale M, Cantoni C, Petretto A, et al. Melanoma cells inhibit natural killer cell function by modulating the expression of activating receptors and cytolytic activity. Cancer Res (2012) 72:1407-15. doi:10.1158/0008-5472.CAN-11-2544

50. Pinton L, Solito S, Damuzzo V, Francescato S, Pozzuoli A, Berizzi A, et al. Activated T cells sustain myeloid-derived suppressor cell-mediated immune suppression. Oncotarget (2016) 7:1168-84. doi:10.18632/oncotarget.6662

51. Chevolet I, Speeckaert R, Schreuer M, Neyns B, Krysko O, Bachert C, et al. Characterization of the in vivo immune network of IDO, tryptophan metabolism, PD-L1, and CTLA-4 in circulating immune cells in melanoma. Oncoimmunology (2015) 4:e982382. doi:10.4161/2162402X.2014. 982382

52. Spranger S, Spaapen RM, Zha Y, Williams J, Meng Y, Ha TT, et al. Up-regulation of PD-L1, IDO, and tregs in the melanoma tumor microenvironment is driven by CD8+ T cells. Sci Transl Med (2013) 5:200ra116. doi:10.1126/ scitranslmed.3006504

53. Spranger S, Koblish HK, Horton B, Scherle PA, Newton R, Gajewski TF. Mechanism of tumor rejection with doublets of CTLA-4, PD-1/PD-L1, or IDO blockade involves restored IL-2 production and proliferation of CD8+ $\mathrm{T}$ cells directly within the tumor microenvironment. J Immunother Cancer (2014) 2:3. doi:10.1186/2051-1426-2-3

54. Melief SM, Visser M, van der Burg SH, Verdegaal EME. IDO and galectin-3 hamper the ex vivo generation of clinical grade tumor-specific $\mathrm{T}$ cells for adoptive cell therapy in metastatic melanoma. Cancer Immunol Immunother (2017) 66(7):913-26. doi:10.1007/s00262-017-1995-x

55. Nefedova Y, Fishman M, Sherman S, Wang X, Beg AA, Gabrilovich DI. Mechanism of all-trans retinoic acid effect on tumor-associated myeloid-derived suppressor cells. Cancer Res (2007) 67:11021-8. doi:10.1158/0008-5472. CAN-07-2593

56. Lee J-M, Seo J-H, Kim Y-J, Kim Y-S, Ko H-J, Kang C-Y. The restoration of myeloid-derived suppressor cells as functional antigen-presenting cells by NKT cell help and all-trans-retinoic acid treatment. Int J Cancer (2012) 131:741-51. doi:10.1002/ijc.26411

57. Iclozan C, Antonia S, Chiappori A, Chen D-T, Gabrilovich D. Therapeutic regulation of myeloid-derived suppressor cells and immune response to cancer vaccine in patients with extensive stage small cell lung cancer. Cancer Immunol Immunother (2013) 62:909-18. doi:10.1007/s00262-013-1396-8 
58. Long AH, Highfill SL, Cui Y, Smith JP, Walker AJ, Ramakrishna S, et al. Reduction of MDSCs with all-trans retinoic acid improves CAR therapy efficacy for sarcomas. Cancer Immunol Res (2016) 4:869-80. doi:10.1158/23266066.CIR-15-0230

59. Joshi S, Singh AR, Zulcic M, Bao L, Messer K, Ideker T, et al. Rac2 controls tumor growth, metastasis and M1-M2 macrophage differentiation in vivo. PLoS One (2014) 9:e95893. doi:10.1371/journal.pone.0095893

60. Holmgaard RB, Zamarin D, Lesokhin A, Merghoub T, Wolchok JD. Targeting myeloid-derived suppressor cells with colony stimulating factor-1 receptor blockade can reverse immune resistance to immunotherapy in indoleamine 2,3-dioxygenase-expressing tumors. EBioMedicine (2016) 6:50-8. doi:10.1016/ j.ebiom.2016.02.024

61. Guo ZS, Liu Z, Kowalsky S, Feist M, Kalinski P, Lu B, et al. Oncolytic immunotherapy: conceptual evolution, current strategies, and future perspectives. Front Immunol (2017) 8:555. doi:10.3389/fimmu.2017.00555

62. Andtbacka RHI, Kaufman HL, Collichio F, Amatruda T, Senzer N, Chesney J, et al. Talimogene laherparepvec improves durable response rate in patients with advanced melanoma. J Clin Oncol (2015) 33:2780-8. doi:10.1200/JCO.2014.58.3377

63. Puzanov I, Milhem MM, Minor D, Hamid O, Li A, Chen L, et al. Talimogene laherparepvec in combination with ipilimumab in previously untreated, unresectable stage IIIB-IV melanoma. JClin Oncol (2016) 34:2619-26. doi:10.1200/JCO.2016.67.1529

64. Sahin TT, Kasuya H, Nomura N, Shikano T, Yamamura K, Gewen T, et al. Impact of novel oncolytic virus HF10 on cellular components of the tumor microenviroment in patients with recurrent breast cancer. Cancer Gene Ther (2012) 19:229-37. doi:10.1038/cgt.2011.80

65. Yamazaki T, Pitt JM, Vétizou M, Marabelle A, Flores C, Rekdal $\varnothing$, et al. The oncolytic peptide LTX-315 overcomes resistance of cancers to immunotherapy with CTLA4 checkpoint blockade. Cell Death Differ (2016) 23:1004-15. doi:10.1038/cdd.2016.35

66. Bansal-Pakala P, Gebre-Hiwot Jember A, Croft M. Signaling through OX40 (CD134) breaks peripheral T-cell tolerance. Nat Med (2001) 7:907-12. doi:10.1038/90942

67. Aris M, Barrio MM. Combining immunotherapy with oncogene-targeted therapy: a new road for melanoma treatment. Front Immunol (2015) 6:46. doi:10.3389/fimmu.2015.00046

68. Mordoh J, Pampena MB, Aris M, Blanco PA, Lombardo M, von Euw EM, et al. Phase II study of adjuvant immunotherapy with the CSF-470 vaccine plus bacillus Calmette-Guerin plus recombinant human granulocyte macrophage-colony stimulating factor vs medium-dose interferon alpha $2 \mathrm{~B}$ in stages IIB, IIC, and III cutaneous melanoma patie. Front Immunol (2017) 8:625. doi:10.3389/fimmu.2017.00625

69. Hoos A, Eggermont AMM, Janetzki S, Hodi FS, Ibrahim R, Anderson A, et al. Improved endpoints for cancer immunotherapy trials. J Natl Cancer Inst (2010) 102:1388-97. doi:10.1093/jnci/djq310

70. Hodi FS, Hwu W-J, Kefford R, Weber JS, Daud A, Hamid O, et al. Evaluation of immune-related response criteria and RECIST v1.1 in patients with advanced melanoma treated with pembrolizumab. J Clin Oncol (2016) 34:1510-7. doi:10.1200/JCO.2015.64.0391
71. Gowrishankar K, Gunatilake D, Gallagher SJ, Tiffen J, Rizos H, Hersey P. Inducible but not constitutive expression of PD-L1 in human melanoma cells is dependent on activation of NF-KB. PLoS One (2015) 10:e123410. doi:10.1371/journal.pone.0123410

72. Zaretsky JM, Garcia-Diaz A, Shin DS, Escuin-Ordinas H, Hugo W, $\mathrm{Hu}$-Lieskovan S, et al. Mutations associated with acquired resistance to PD-1 blockade in melanoma. N Engl J Med (2016) 375:819-29. doi:10.1056/ NEJMoa1604958

73. Shin DS, Zaretsky JM, Escuin-Ordinas H, Garcia-Diaz A, Hu-Lieskovan S, Kalbasi A, et al. Primary resistance to PD-1 blockade mediated by JAK1/2 mutations. Cancer Discov (2017) 7:188-201. doi:10.1158/2159-8290.CD-16-1223

74. Sunshine J, Taube JM. PD-1/PD-L1 inhibitors. Curr Opin Pharmacol (2015) 23:32-8. doi:10.1016/j.coph.2015.05.011

75. Kluger HM, Zito CR, Barr ML, Baine MK, Chiang VLS, Sznol M, et al. Characterization of PD-L1 expression and associated T-cell infiltrates in metastatic melanoma samples from variable anatomic sites. Clin Cancer Res (2015) 21:3052-60. doi:10.1158/1078-0432.CCR-14-3073

76. Obeid JM, Erdag G, Smolkin ME, Deacon DH, Patterson JW, Chen L, et al. PD-L1, PD-L2 and PD-1 expression in metastatic melanoma: correlation with tumor-infiltrating immune cells and clinical outcome. Oncoimmunology (2016) 5:e1235107. doi:10.1080/2162402X.2016.1235107

77. Kubeček O, Kopecký J. Microsatellite instability in melanoma. Melanoma Res (2016) 26:545-50. doi:10.1097/CMR.0000000000000298

78. Sanmamed MF, Carranza-Rua O, Alfaro C, Oñate C, Martín-Algarra S, Perez G, et al. Serum interleukin- 8 reflects tumor burden and treatment response across malignancies of multiple tissue origins. Clin Cancer Res (2014) 20:5697-707. doi:10.1158/1078-0432.CCR-13-3203

79. Sanmamed MF, Perez-Gracia JL, Schalper KA, Fusco JP, Gonzalez A, Rodriguez-Ruiz ME, et al. Changes in serum interleukin-8 (IL-8) levels reflect and predict response to anti-PD-1 treatment in melanoma and non-small cell lung cancer patients. Ann Oncol (2017) 28(8):1988-95. doi:10.1093/annonc/ mdx190

80. Cabel L, Riva F, Servois V, Livartowski A, Daniel C, Rampanou A, et al. Circulating tumor DNA changes for early monitoring of anti-PD1 immunotherapy: a proof-of-concept study. Ann Oncol (2017) 28(8):1996-2001. doi:10.1093/annonc/mdx212

81. Lee JH, Long GV, Boyd S, Lo S, Menzies AM, Tembe V, et al. Circulating tumour DNA predicts response to anti-PD1 antibodies in metastatic melanoma. Ann Oncol (2017) 28:1130-6. doi:10.1093/annonc/mdx026

Conflict of Interest Statement: The authors declare that the research was conducted in the absence of any commercial or financial relationships that could be construed as a potential conflict of interest.

Copyright (C) 2017 Aris, Mordoh and Barrio. This is an open-access article distributed under the terms of the Creative Commons Attribution License (CC BY). The use, distribution or reproduction in other forums is permitted, provided the original author(s) or licensor are credited and that the original publication in this journal is cited, in accordance with accepted academic practice. No use, distribution or reproduction is permitted which does not comply with these terms. 